\title{
Consumption-based Asset Pricing with Loss Aversion*
}

\author{
Marianne Andries ${ }^{\dagger}$ \\ Chicago Booth School of Business
}

October, 2011

\begin{abstract}
I incorporate loss aversion in a consumption-based asset pricing model with recursive preferences and solve for asset prices in closed-form. I find loss aversion increases expected returns substantially relative to the standard recursive utility model. This feature of my model improves the ability to match moments on asset prices. Further, I find loss aversion induces important nonlinearities into the expected excess returns as a function of the exposure to the consumption shocks. In particular, the elasticities of expected returns with respect to the exposure to the consumption shocks are greater for assets with smaller exposures to the shocks, thus generating interesting predictions for the cross-section of returns. I provide strong empirical evidence supporting this outcome. The model with loss aversion correctly predicts both a negative premium for skewness and a security market line, the excess returns as a function of the exposure to market risk, flatter than the CAPM.
\end{abstract}

\section{Introduction}

Loss-averse agents value consumption outcomes relative to a reference point, and losses relative to the reference create more disutility than comparable gains. I add such loss aversion features to a preference model with recursive utility, in which the present value of the consumption stream depends on current consumption and next period's value for future consumption. I suppose agents are loss averse and thus suffer additional disutility if the realization of next period's value disappoints (i.e., falls below their expectation). My model of loss aversion allows me to find tractable solutions to the consumption-based asset pricing model with homogeneous agents. Allowing for loss aversion in the preferences impacts asset prices greatly. Compared to the standard recursive

*I want to thank my committee chairs, Lars Peter Hansen and Pietro Veronesi, and my committee members, John C. Heaton, Emir Kamenica, Ralph Koijen. Also for their comments and advice, I want to thank Thomas Chaney, Nicolas Coeurdacier, John Cochrane, George Constantinides, Andrea Frazzini, Xavier Gabaix, Valentin Haddad, Botond Koszegi, Junghoon Lee, Nan Li, Erik Loualiche, Shrihari Santosh and David Sraer.

${ }^{\dagger}$ Contact: Booth School of Business, Chicago, IL 60637. Tel: 312-307-2159. Email: mandries@chicagobooth.edu . 
utility model, I find (i) the loss aversion specification induces important nonlinearities in the expected excess returns: the risk-price elasticities, the elasticities of expected returns with respect to the exposure to the consumption shocks, vary with the exposures to the shocks (cross-sectional effect); and (ii) even small parameters of loss aversion increase expected returns substantially (level effect).

Consider first the cross-sectional effect. In my model with loss aversion, the risk-price elasticities are lower for assets with high exposures to the consumption shocks and higher for assets with low exposures to the shocks. In contrast, in the cases I consider, the standard recursive utility model generates risk-price elasticities that are constant across exposures to the consumption shocks. My model with loss aversion thus generates novel predictions for the cross section of returns, which truly differentiate it from the standard recursive utility model. Two well-known results in finance provide strong empirical support for my model. First, Black, Jensen, and Scholes (1972) and more extensively Frazzini and Pedersen (2010) show the asset returns line (the excess returns as a function of beta, the exposure to market risk) is persistently flatter over time than the CAPM, for a wide class of assets (U.S. equities, 20 global equity markets, Treasury bonds, corporate bonds, and futures). My model with loss aversion offers a new theoretic explanation for these results. Unlike previous models that address this finding, my model does not require borrowing constraints or agent heterogeneity. Second, Harvey and Siddique (2000) show that assets with the same volatility but different skewness in their returns distributions yield different expected returns: they find a negative premium for skewness. My model with loss aversion predicts such a negative premium for skewness.

Let us now turn to the level effect. With loss aversion, my model generates higher expected excess returns and lower risk-free rates than in the standard recursive utility model. The recursive utility model, which allows one to disentangle the risk aversion and the intertemporal elasticity of substitution, is central to the consumption-based asset pricing literature, notably the long-run risk models (e.g., Bansal and Yaron (2004); Hansen, Heaton, and Li (2008); Bansal, Kiku, and Yaron $(2007,2009))$. However, its calibration using moments on asset returns requires high levels of risk aversion. The level effect my model with loss aversion generates allows me to improve on such calibration exercises.

Beyond the contribution of developing a fully tractable consumption-based asset pricing model with loss aversion, my analysis of the cross-sectional risk-price elasticities, as well as the impact of loss aversion on the security market line relative to the CAPM, is novel to the behavioral finance 
and the asset pricing literature.

Previous papers analyze the impact on asset prices of preferences with loss aversion (e.g., Benartzi and Thaler (1995); Barberis et al. (2001); Yogo (2008); Barberis and Huang (2009)). I add to this literature by defining a new model of preferences with loss aversion that allows me to solve the asset pricing model with recursive utility in a tractable way. The advantage of using recursive preferences in consumption-based asset pricing models is well established, particularly for the long-run risk models. Combining behavioral models and recursive utility gives rise to interesting results. Other authors have adopted this approach. Routledge and Zin (2010) present a model of generalized disappointment aversion, an extension of the disappointment aversion of Gul (1991). They analyze the asset pricing implications of Epstein-Zin preferences with generalized disappointment aversion and obtain closed-form solutions and interesting results in a simple twostate Markov economy. Bonomo et al. (2011) extend the analysis to a four-state Markov adapted from Bansal, Kiku, and Yaron (2007). They match first and second moments on the market returns and risk-free rate, predictability patterns, and autocorrelations, for realistic parameters. The tractable features of my model allow me to find closed-form solutions for more general economies, and to analyze and derive solutions for various novel reference-point models, while remaining close in spirit to disappointment aversion. Barberis and Huang (2009) use a recursive utility model with loss aversion narrow framed on the stock market returns and find closed-form solutions for both partial and general equilibria. My model differs from theirs in two crucial ways. First, I do not opt for narrow framing on financial risks. This is a more conservative choice which makes the results I obtain all the more robust. Second, Barberis and Huang (2009) choose the constant risk free rate as the reference point for market returns. My model, in which the reference point is endogenously determined as an expectation, better reflects empirical evidence on the reference point.

The rest of the paper is organized as follows: In section 1, I model loss aversion in a recursive model of preferences. In section 2, I analyze the consumption-based asset pricing model and obtain tractable solutions for the model of preferences with loss aversion. I then analyze the asset pricing implications of the model. The predictions of the model are brought to the data in section 3.

\section{Preferences with Loss Aversion}

I define a new model of preferences that display loss aversion, with a reference point endogenously specified as an expectation of the future utility of consumption. I focus on CRRA preferences and 
a log-linear specification, which allows me to obtain closed-form solutions when adapted to the consumption-based asset pricing model with unit intertemporal elasticity of substitution.

In this section, I define how I model loss aversion and how I incorporate it in the recursive utility model of Epstein and Zin (1989). For illustrative purposes, I start with a two-period model in section 1.1. In section 1.2, I extend the loss aversion specification to the multi-period, recursive utility model, and I fully describe my choice of preferences.

\section{$1.1 \quad$ Two-Period Model}

Consider first a two-period model. At period $t=1$, the agent receives consumption $C$, the level of which is uncertain at period $t=0$.

The standard CRRA model for this two-period setting is:

$$
U_{0}=\mathbb{E}\left(\frac{C^{1-\gamma}}{1-\gamma} \mid \mathcal{I}_{0}\right)
$$

where $\mathcal{I}_{0}$ is the information set at time $t=0$ and $\gamma>1$ is the coefficient of risk aversion.

\section{With Loss Aversion}

I modify the standard model by adding loss aversion in the preferences.

First, I suppose that preferences are continuous and display a kink at a reference point $\mathcal{R}(C)$, which I define later. Relative to the reference point, losses create more disutility than comparable gains, and thus the slope of the utility function with respect to consumption is steeper on the left-hand side of the reference point $\mathcal{R}(C)$ than on the right-hand side. The more loss averse the agent is, the sharper the kink in the preferences will be. I define a loss aversion coefficient $\alpha \in[0,1)$, which measures how sharp the kink is. $1-\alpha$ determines the ratio of the right-hand slope to the left-hand slope. In the limit case $\alpha=0$, the agent displays no loss aversion (the ratio of the slopes is exactly one) and the model reverts to the standard CRRA model. As $\alpha$ increases, so does the sharpness of the kink at the reference point. Using micro evidence, Kahneman and Tversky (1979) estimate the ratio of the slopes at $1 / 2.25$, which corresponds to $\alpha=0.55$.

Second, to ensure tractability in the asset pricing model, I choose to maintain the CRRA specification above and below the reference point $\mathcal{R}(C)$. I also impose homogeneity in the preferences, which is a requirement for tractable solutions to the recursive utility model. I suppose that above the reference point $\mathcal{R}(C)$, the agent's utility is unchanged as CRRA with risk aversion $\gamma$. 
Proposition 1 If preferences $U(C, \mathcal{R}(C))$ satisfy:

1) preferences are continuous

2) preferences display a kink at a reference point $\mathcal{R}(C)$.

3) at the reference point, the ratio of the right-hand slope relative to the left-hand slope is equal to $1-\alpha$ with $\alpha \in[0,1)$

4) preferences are homogeneous CRRA above and below the reference point, Then:

$$
U(C, \mathcal{R}(C))=\left\{\begin{array}{ll}
a \frac{C^{1-\bar{\gamma}}}{1-\bar{\gamma}} & \text { for } C \leq \mathcal{R}(C) \\
b \frac{C^{1-\gamma}}{1-\gamma} & \text { for } C \geq \mathcal{R}(C)
\end{array},\right.
$$

with $\frac{b}{a}=\frac{1-\gamma}{1-\bar{\gamma}}(\mathcal{R}(C))^{\gamma-\bar{\gamma}}$ and $\frac{1-\gamma}{1-\bar{\gamma}}=1-\alpha$.

Proof. Proof is given in Appendix B.

Consider the two-period model given by:

$$
U_{0}=\mathbb{E}\left(U(C, \mathcal{R}(C)) \mid \mathcal{I}_{0}\right)
$$

where

$$
\left\{\begin{array}{ll}
U(C, \mathcal{R}(C))=a \frac{C^{1-\bar{\gamma}}}{1-\bar{\gamma}} & \text { for } C \leq \mathcal{R}(C) \\
U(C, \mathcal{R}(C))=b \frac{C^{1-\gamma}}{1-\gamma} & \text { for } C \geq \mathcal{R}(C)
\end{array} .\right.
$$

In Figure 1, I illustrate how my model incorporates loss aversion into the standard CRRA twoperiod model. The utility from consumption is continuous and displays a kink at the reference point. Above the reference point, the utility from consumption has the same curvature as in the standard CRRA model. The coefficient of risk aversion $\gamma$ is unchanged. Below the reference point, the loss aversion specification results in a decrease in utility relative to the standard model. The curvature is stronger and the resulting risk aversion below the reference point, $\bar{\gamma}$, is higher than in the standard model: $\bar{\gamma} \geq \gamma$ where $\bar{\gamma}$ is a function of $\gamma$ and $\alpha$, the coefficient of loss aversion.

In the prospect theory model of Kahneman and Tversky (1979), agents display loss aversion in their preferences, with risk aversion above and risk seeking below the reference point. However, in order to obtain tractable asset pricing solutions with my model of preferences, I cannot maintain risk-seeking below the reference point. Indeed, as evidenced by Proposition 1, the risk seeking feature of the prospect theory model cannot be preserved with homogeneous CRRA preferences.

The ratio of the slopes above and below the reference point is given by

$$
\frac{1-\gamma}{1-\bar{\gamma}}=1-\alpha
$$




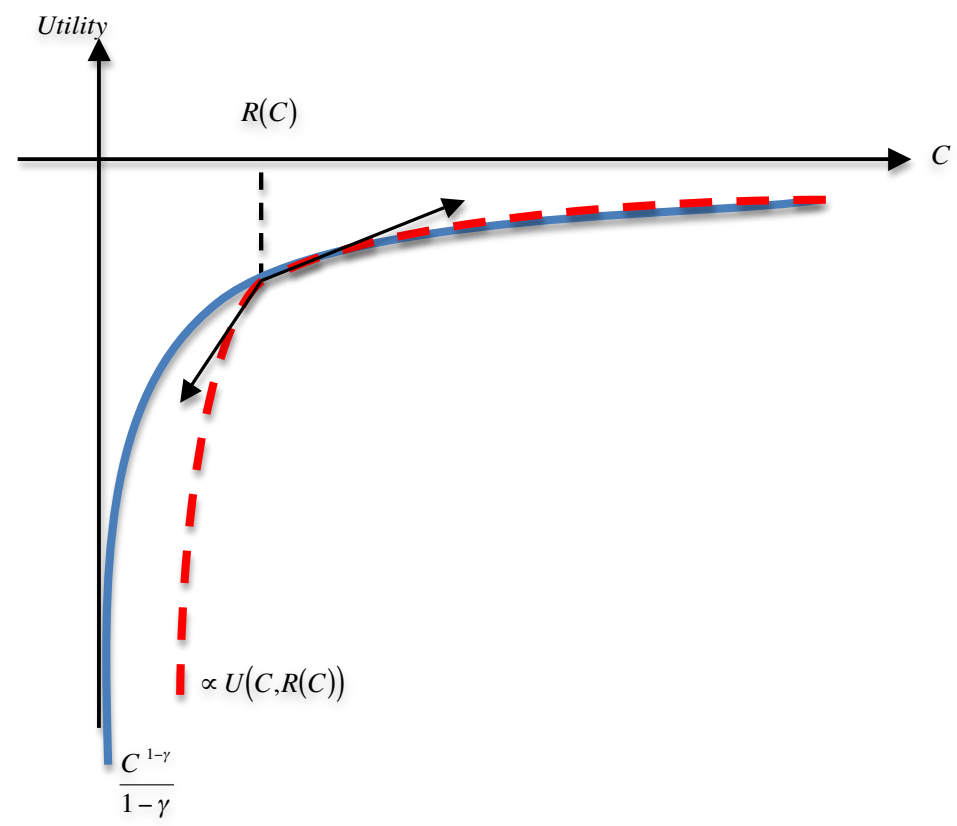

Figure 1: Loss Aversion in the Two-period Model

This equation makes explicit $\bar{\gamma}$ as an increasing function of both $\gamma$ and $\alpha$.

To ensure the continuity of the preferences at the reference point, the scaling coefficients in $U(C, \mathcal{R}(C))$ must be such that

$$
\frac{b}{a}=\frac{1-\gamma}{1-\bar{\gamma}}(\mathcal{R}(C))^{\gamma-\bar{\gamma}}
$$

Without loss of generality, I can set $b=1$ or $a=1$. As I discuss below, I model the reference point $\mathcal{R}(C)$ as an expectation of future consumption outcomes, and it is thus endogenously determined by the agent's optimal consumption choice. Because the agent is loss averse for outcomes below the reference point, choosing a consumption path that results in a low reference point rather than a high reference point at period $t+1$, thus decreasing the probability of disappointment, could be in her best interest. In such a case, the agent would sometimes reject first-order dominating outcomes. Some empirical evidence exists regarding such behavior. Frederick and Loewenstein (1999) consider cases in which a prisoner is better off not trying for parole in order to avoid being disappointed. Gneezy, List, and Wu (2006) observe cases in which an agent chooses a worst outcome for certain rather than a lottery outcome. ${ }^{1}$ However, in the context of asset pricing, first-order stochastic dominance should be preserved to avoid direct violations of the no-arbitrage condition. In that regard, I follow Kahneman and Tversky (1979), in which direct violation of

\footnotetext{
${ }^{1}$ See also Akerlov and Dickens (1982) and Matthey (2010).
} 
dominance is prevented in the first stage of editing.

Consequently, I ensure, in my model of preferences, the expected utility $U_{0}$ is increasing in $\mathcal{R}(C)$. This is satisfied when $a=1$ and:

$$
U(C, \mathcal{R}(C))=\frac{1}{1-\bar{\gamma}} \begin{cases}C^{1-\bar{\gamma}} & \text { for } C \leq \mathcal{R}(C) \\ C^{1-\gamma} \times \underbrace{(\mathcal{R}(C))^{\gamma-\bar{\gamma}}}_{\text {scaling factor }} & \text { for } C \geq \mathcal{R}(C)\end{cases}
$$

Note that in my model, agents display loss aversion over the total value of consumption. Rabin (2000) points out that in lab experiments, agents tend to reject small favourable gambles. For expected utility agents to reject small favourable gambles, as is observed in the data, the risk aversion coefficient has to be so high that extremely favourable large gambles are also rejected. Barberis, Huang, and Thaler (2006) analyze which preferences allow for agents to reject a small gamble $G_{S}=$ $\left[\left(550, \frac{1}{2}\right),\left(-500, \frac{1}{2}\right)\right]$ while also accepting a large gamble $G_{L}=\left[\left(20,000,000, \frac{1}{2}\right),\left(-10,000, \frac{1}{2}\right)\right]$. They show that first-order risk aversion (a kink in the preferences) can justify such behavior. However, first-order risk aversion alone is not sufficient. Indeed, if all risks are evaluated together, the authors argue the diversification effect of gambles with independent risk dominates and the agent behaves as if she is second-order risk averse. They propose to combine first-order risk aversion with narrow framing, a process in which new gambles are evaluated independently from all other risky revenue sources. Barberis, Huang, and Santos (2001) and Barberis and Huang (2009) apply this model to asset pricing. Because stock market returns have a low correlation with consumption growth, the impact of the loss aversion specification is much stronger if the agent narrow frames on the stock market returns, and even a small coefficient of loss aversion can substantially increase stock returns. I make the more conservative choice of a consumption-based model without narrow framing, with the view that the results I obtain would only be enhanced if I introduced some narrow framing.

\section{Reference Point}

I model a reference point endogenously determined by the agent's expectation of outcomes given $\mathcal{I}_{0}$, the information at time $t=0$. Koszegi and Rabin (2006) give a detailed argument as to why the reference point should be determined by the agent's expectation of outcomes. ${ }^{2}$ Empirical

\footnotetext{
${ }^{2}$ In their model, the reference point is a stochastic expectation, the expectation over distributions of future outcomes. As a special case, when all uncertainty is resolved at period $t=1$, the stochastic reference point of the Koszegi-Rabin model collapses to a fixed point, as in my model.
} 
evidence for the reference point as an expectation in the model of Koszegi and Rabin (2006) has been found in Post et al. (2008), Eil and Lien(2010), Sprenger (2010), and Crowford and Meng (2011). In Appendix A, I discuss my modelling choices for loss aversion, and relate them to the existing literature, in particular to the model of Koszegi and Rabin (2006). Because my model and the one of Koszegi and Rabin (2006) have similar features, the empirical evidence also validates my choice of the reference point as an endogenous expectation of outcomes.

I choose a log-linear specification for the reference point: in my model, the agent is disappointed and registers additional disutility from loss aversion when $\log C \leq \mathbb{E}\left(\log C \mid \mathcal{I}_{0}\right)$. When $\log C \geq$ $\mathbb{E}\left(\log C \mid \mathcal{I}_{0}\right)$, the agent's utility from consumption is unchanged. The threshold for consumption below which the agent registers disutility from loss aversion is thus $\mathcal{R}(C)=\exp \left(\mathbb{E}\left(\log C \mid \mathcal{I}_{0}\right)\right)$.

The log-linear specification for the reference point is a natural choice for the consumption-based asset pricing model with unit intertemporal elasticity of substitution. However, the model can be solved for other choices of the reference point as an expectation. In particular, the predictions of my model are largely unchanged by the choice of $\mathcal{R}(C)=\mathbb{E}\left(C \mid \mathcal{I}_{0}\right)$.

My model for the reference point is similar in spirit to the disappointment aversion model (in which the reference point is the endogenous certainty equivalent). However, in my model, the reference point is explicitly defined as an expectation, whereas in the disappointment aversion model, it is the solution to a recursive problem. My model allows for greater flexibility in the choice of the reference point and is more tractable. In particular, the log-linear specification for the reference point, which simplifies the solutions to the asset pricing model significantly, would not obtain in the disappointment aversion model.

\subsection{Multi-Period Model, Recursive Utility}

I now consider a multi-period model with consumption stream $\left\{C_{t}\right\}$. My choice for the standard preference model is the recursive utility model of Epstein and Zin (1989). In the asset pricing literature, this model of preferences in which the risk aversion coefficient is disentangled from the intertemporal elasticity of substitution allows one to obtain realistic moments in the distributions of prices. In particular, it generates low risk-free rates along with high stock returns. Further, in contrast to the expected utility model, this model of preferences allows the shocks to long-run consumption to impact current prices.

At each period $t$, the agent's valuation for the future consumption stream is given by $V_{t}$, which 
is defined recursively as:

$$
V_{t}=\left((1-\beta) C_{t}^{1-\rho}+\beta\left(h\left(V_{t+1}\right)\right)^{1-\rho}\right)^{\frac{1}{1-\rho}}
$$

with $\rho>0$ the inverse of the EIS (elasticity of intertemporal substitution) and $0<\beta<1$ the discount factor (with $-\log \beta$ the rate of time discount).

In the standard model, $h$ is given by:

$$
h\left(V_{t+1}\right)=\left(\mathbb{E}_{t}\left(V_{t+1}^{1-\gamma}\right)\right)^{\frac{1}{1-\gamma}}
$$

where $\gamma>1$ is the coefficient of risk aversion.

\section{With Loss Aversion}

In the recursive utility model, the next period consumption $C_{t+1}$ of the two-period model is replaced by $V_{t+1}$, the value of all future consumption. Similarly to the two-period model of section (1.1), I modify the standard recursive utility model by introducing loss aversion around a reference point $\mathcal{R}_{t}\left(V_{t+1}\right)$, and I define $h$ as

$$
h\left(V_{t+1}\right)=\left\{\mathbb{E}_{t}\left[U\left(V_{t+1}, \mathcal{R}_{t}\left(V_{t+1}\right)\right)\right]\right\}^{\frac{1}{1-\bar{\gamma}}},
$$

where

$$
U\left(V_{t+1}, \mathcal{R}_{t}\left(V_{t+1}\right)\right)= \begin{cases}V_{t+1}^{1-\bar{\gamma}} & \text { for } V_{t+1} \leq \mathcal{R}_{t}\left(V_{t+1}\right) \\ V_{t+1}^{1-\gamma} \times \underbrace{\left(\mathcal{R}_{t}\left(V_{t+1}\right)\right)^{\gamma-\bar{\gamma}}}_{\text {scaling factor }} & \text { for } V_{t+1} \geq \mathcal{R}_{t}\left(V_{t+1}\right)\end{cases}
$$

and

$$
\frac{1-\gamma}{1-\bar{\gamma}}=1-\alpha
$$

Eq. (2) is the multi-period extension to the two-period model of Eq. (1).

As in the two-period model, loss aversion is represented by one coefficient, $\alpha \in[0,1)$ which determines the sharpness of the kink in the preferences. When $\alpha=0$, the agent displays no loss aversion and my model reverts to the standard recursive utility model. When $\alpha>0$, the agent is loss averse and expects at time $t$ to experience additional disutility at time $t+1$ if the value of the future consumption stream $V_{t+1}$ is disappointing, that is, falls below her time $t$ reference point $\mathcal{R}_{t}\left(V_{t+1}\right)$. The agent expects the utility at time $t+1$ to display a kink at the reference point $\mathcal{R}_{t}\left(V_{t+1}\right)$ with a ratio of slopes given by $1-\alpha=(1-\gamma) /(1-\bar{\gamma})$ as in Eq. (3). As before, this relation makes explicit $\bar{\gamma}$ as an increasing function of both $\gamma$ and $\alpha$. 
Note that I did not include loss aversion on the contemporaneous consumption $C_{t}$. Although doing so is feasible, it would complicate the solution to the asset pricing model substantially. Besides, the one-period discount rate is sufficiently low that most of the value in $V_{t}$ comes from the second term in $V_{t+1}$ and not from the first term in $C_{t}$. Simplifying the model by restricting the loss aversion specification to the second term in $V_{t+1}$ is a valid choice.

Further, I did not include loss aversion over changes in the reference point $\mathcal{R}_{t}\left(V_{t+1}\right)$. Koszegi and Rabin (2009) propose a model without narrow framing in which agents remain first-order risk averse for choices over small and large gambles. In their model, agents are loss averse in the news about future outcomes. This type of modelization may be adapted to my model. Adding loss aversion over changes in the reference point is left for future research.

\section{Reference Point}

As in the two-period model, the agent's reference point is an expectation of future outcomes. As discussed in Koszegi and Rabin (2006), the agent updates her reference point as an expectation when new information about future outcomes becomes available. However, the manner with which the agent updates the reference point is a modelling choice.

Suppose the agent fully updates her reference point at each period, such that the reference point at time $t$ is an expectation of outcomes at time $t+1$ given the information $\mathcal{I}_{t}$. As I show in section 2.1, this model is tractable and yields interesting results for asset prices. Whether or not the agent is disappointed depends solely on the shocks to the consumption process between $t$ and $t+1$ : the distribution of disappointment (and thus the price of risk) is constant if the consumption process is homoskedastic and varying only if the consumption process is heteroskedastic.

Now suppose the agent's reference point at time $t$ depends on past expectations of the period $t+1$ outcomes. The agent partly updates the reference point at each period but does not modify the reference point all the way to the new expectation. Her reference point is a weighted average of current and past expectations as in

$$
\mathcal{R}_{t}\left(V_{t+1}\right)=\left(\prod_{n=0}^{T}\left(u^{-1}\left(\mathbb{E}\left(u\left(V_{t+1}\right) \mid \mathcal{I}_{t-n}\right)\right)\right)^{\xi^{n}}\right)^{\frac{1}{\sum_{0}^{T} \xi^{n}}}
$$

where $\xi \in[0,1), T$ is the number of past periods impacting the reference point, and the function $u$ is a modeling choice for the reference point. The case $\xi=0$ reverts to the model where the reference point is fully updated at each period and only current expectations matter. 
Dillenberger and Rozen (2011) argue for a history-dependent risk attitude (past disappointments and elation have an impact on risk aversion), which would support a model of "sticky" updating of the reference point, and $\xi>0$. On the other hand, price-dividend ratios are not predicted in the data by past consumption growth (which is also a critique of all habit models), which tends to suggest the degree of "stickiness" $\xi$ must remain small.

When $\xi>0$, the agent gradually upgrades the reference point following positive shocks to the consumption process and thus the risk of disappointment diminishes. Conversely, the reference point is gradually downgraded in a recession and thus the risk of disappointment increases. As a consequence, the price of risk varies in a counter-cyclical manner, low following an expansion and high following a recession, even when the consumption process has constant volatility.

The need for asset pricing models with a counter-cyclical price of risk is illustrated in Melino and Yang (2003). In this paper, the authors show that in a two-state economy, the empirical pricing kernel that matches asset prices displays a higher price of risk in the bad state. Campbell and Cochrane (1999) introduce a habit model in which time-varying risk aversion obtains from an exogenous habit level, specified independently from the consumption process. Similarly, Barberis, Huang, and Santos (2001) introduce a time-varying price of risk through a loss aversion parameter that is directly specified as time varying and counter-cyclical. Yogo (2008) analyzes a loss aversion model in which external habit formation determines the reference point. In all these models, timevarying risk aversion is exogenously enforced. In contrast, counter-cyclical risk prices endogenously obtain in my model with "sticky" updating of the reference point. ${ }^{3}$

As in the two-period model, I choose a log-linear specification for the reference point. At time $t$, the agent expects to be disappointed at time $t+1$ when:

$$
\log V_{t+1} \leq \frac{\sum_{n=0}^{T} \xi^{n} \mathbb{E}\left(\log V_{t+1} \mid \mathcal{I}_{t-n}\right)}{\sum_{n=0}^{T} \xi^{n}}
$$

In this set-up, the threshold for the value function $V_{t+1}$ to be disappointing is

$$
\mathcal{R}_{t}\left(V_{t+1}\right)=\left(\prod_{n=0}^{T}\left(\exp \mathbb{E}\left(\log V_{t+1} \mid \mathcal{I}_{t-n}\right)\right)^{\xi^{n}}\right)^{\frac{1}{\sum_{0}^{T} \xi^{n}}}
$$

In the analysis of the consumption-based asset pricing model, I consider first the case $\xi=0$, for which

$$
\mathcal{R}_{t}\left(V_{t+1}\right)=\exp \left[\mathbb{E}\left(\log V_{t+1} \mid \mathcal{I}_{t}\right)\right] .
$$

\footnotetext{
${ }^{3}$ Observe that the model with "sticky" updating, $\xi>0$, is not a permissible modelling choice in the disappointment aversion model.
} 
I then analyze the time variation induced by $\xi>0, T>0$.

\section{Characteristics of the Model}

Combining the model of Eq. (2) and the modeling choice for the reference point of Eq. (4), my recursive utility model with loss aversion can be rewritten as

$$
\begin{aligned}
V_{t} & =\left((1-\beta) C_{t}^{1-\rho}+\beta\left(h\left(V_{t+1}\right)\right)^{1-\rho}\right)^{\frac{1}{1-\rho}} \\
h\left(V_{t+1}\right) & =\mathbb{E}_{t}\left(\bar{V}_{t+1}{ }^{1-\bar{\gamma}}\right)^{\frac{1}{1-\bar{\gamma}}} \\
\log \overline{V_{t+1}} & =\log V_{t+1}-\alpha \max \left(0, \log V_{t+1}-\left(\frac{1-\xi}{1-\xi^{T+1}}\right) \sum_{n=0}^{T} \xi^{n} \mathbb{E}_{t-n}\left(\log V_{t+1}\right)\right) \\
\rho & >0, \beta \in[0,1), \alpha \in[0,1), \bar{\gamma}=\gamma+\frac{\alpha}{\alpha-1}(\gamma-1) \geq \gamma>1, T \geq 0, \xi \in[0,1),
\end{aligned}
$$

where $\alpha$ is the coefficient of loss aversion. When $\alpha=0$, my model reverts to the standard recursive utility model.

Proposition 2 h has the following properties:

1) if the outcome $V_{t+1}$ is certain, $h\left(V_{t+1}\right)=V_{t+1}$

2) $h$ is increasing (first-order stochastic dominance)

3) $h$ is concave (second-order stochastic dominance)

4) $h$ is homogeneous of degree one (and therefore $V_{t}$ is homogeneous of degree one in $\left(C_{t}, V_{t+1}\right)$ )

Proof. Proof of these properties is provided in Appendix C.

These characteristics of my model allow me to use most of the results from Epstein and Zin (1989), notably the uniqueness of the solution to the optimization problem. The concavity in the preferences justifies the use of first-order conditions at the optimum. Because at time $t, V_{t}$ is increasing in $V_{t+1}$ (first-order stochastic dominance), my model of preferences is time consistent.

Notice this is a discrete time model in which the length of time intervals can greatly influence the impact of loss aversion. Indeed, for any time period $T$, the probability that the agent experiences some loss aversion increases with the frequency of the model. Therefore, for a given coefficient of loss aversion $\alpha$, the impact of the loss aversion specification on asset prices increases with the frequency of the discrete time model. At the continuous time limit, the probability of disappointment on any period of time goes to one, and the agent would refuse to take any form 
of risk. As an extension to this paper, it would be interesting to consider a model in which the coefficient of loss aversion $\alpha$ decreases with the frequency of the model. Depending on how fast $\alpha$ decreases with the frequency, the continuous time limit could remain well behaved. This extension is left for future research.

\section{Consumption-based Asset Pricing Model}

I assume all agents have identical preferences with loss aversion, given by Eq. (5), and that they differ only in their wealth. ${ }^{4}$ Because preferences are homothetic, the representative agent assumption is justified.

I suppose that the optimal consumption follows a conditionally log-normal process with timevarying drift and volatility:

$$
\begin{aligned}
\log C_{t+1}-\log C_{t} & =\mu_{c}+\phi_{c} X_{t}+\sigma_{t} \Sigma_{c} W_{t+1} \\
X_{t+1} & =A X_{t}+\sigma_{t} \Sigma_{X} W_{t+1} \\
\sigma_{t+1} & =(1-a)+a \sigma_{t}+\Sigma_{\sigma} W_{t+1} .
\end{aligned}
$$

$\left\{W_{t}\right\}$ is a three-dimension vector of shocks, iid $\mathcal{N}(0, I)$. $A$ and $a$ are contracting (all eigen values have module strictly less than one): both state variables have stationary distributions, with mean zero for $\left\{X_{t}\right\}$ and mean one for the scalar $\left\{\sigma_{t}\right\}$.

The log consumption growth has a slow-moving drift with mean value $\mu_{c}$ and time-varying component $\phi_{c} X_{t}$. The immediate consumption shock, $\sigma_{t} \Sigma_{c} W_{t+1}$, has time varying volatility. A second shock with time varying volatility, $\sigma_{t} \Sigma_{X} W_{t+1}$, impacts the slow-moving drift of consumption growth through the state variable $X_{t}$. The second shock does not impact consumption at first but its effect builds over time and impacts consumption in the long-run. Finally, a third shock, the volatility shock $\Sigma_{\sigma} W_{t+1}$, impacts the volatility of the consumption process through the state variable $\sigma_{t}$. In contrast to the other shocks, the volatility shocks are identically distributed over time. To simplify the model, volatility shocks are supposed to be independent from expected consumption shocks: $\Sigma_{\sigma} \Sigma_{X}^{\prime}=\Sigma_{\sigma} \Sigma_{c}^{\prime}=0$.

For illustrative purposes, most solutions are presented in the specific case $\Sigma_{\sigma}=0$ ( consumption process with constant volatility).

\footnotetext{
${ }^{4}$ Discussing the possible impact of heterogeneity in preferences is not in the scope of this paper, but would be worth exploring. The equilibrium existence, representative agent, and PDE solutions of Duffie and Lyons (1992) and Skiadas and Schroder (1999) cannot be used because the preferences are not continuously differentiable in the interior domain.
} 
In sections 2.1 and 2.2, I analyze the consumption-based asset pricing model with the preferences of Eq. (5) and obtain tractable solutions for the case $\xi=0$ (full updating of the reference point). I find the loss aversion specification has (i) a level effect: the expected excess returns are higher and the risk-free rate is lower than in the standard recursive utility model; and (ii) a cross-sectional effect: depending on the exposures to the consumption shocks, the impact of loss aversion is more or less intense.

In section 2.3, I present tractable solutions for the model with "sticky" updating, $\xi>0$, and I obtain counter-cyclical risk-price elasticities.

To illustrate the results, I use the consumption process parameters of Hansen, Lee, Polson, and Yae (2011). In the case with constant volatility, I use the consumption process parameters of Hansen, Heaton, and Li (2008). Their empirical set up is discussed in section 3.

\subsection{Solving the Consumption-Based Asset Pricing Model}

Following the methodology of Hansen, Heaton, Lee, and Roussanov (2007), the model with full updating of the reference point $(\xi=0)$ is first solved in closed-form for a unit elasticity of intertemporal substitution (case $\rho=1$ ). A first-order Taylor expansion around $\rho=1$ allows me to analyze the model for $\rho \neq 1 .^{5}$

Write $\log C=c, \log V=v, \log \bar{V}=\bar{v}$ and $v^{1}=\left.v\right|_{\rho=1}$.

When $\xi=0$ and $\rho=1$, the model of Eq. (5) becomes:

$$
\begin{aligned}
v_{t}^{1} & =(1-\beta) c_{t}+\frac{\beta}{1-\bar{\gamma}} \log \mathbb{E}_{t}\left[\exp (1-\bar{\gamma}) \overline{v_{t+1}^{1}}\right] \\
\overline{v_{t+1}^{1}} & =v_{t+1}^{1}-\alpha \max \left(0, v_{t+1}^{1}-\mathbb{E}_{t}\left(v_{t+1}^{1}\right)\right) .
\end{aligned}
$$

Because $\overline{v^{1}}$ is increasing in $v^{1}$, this recursive problem trivially follows Blackwell conditions, and thus admits a unique solution.

A first-order Taylor expansion around $\rho=1$ yields:

$$
v_{t}=v_{t}^{1}+(\rho-1) D v_{t}^{1} .
$$

\footnotetext{
${ }^{5}$ There is some debate concerning the value of the elasticity of intertemporal substitution. Both the long-run risk model of Bansal and Yaron (2004) and Bansal, Kiku, and Yaron (2007, 2009) and the disaster model of Barro et al. (2011) require $E I S \geq 1$ to explain the equity returns. A large number of papers (Hansen and Singleton (1982), Attanasio and Weber (1989), Beaudry and van Wincoop (1996), Vissing-Jorgensen (2002), Attanasio and Vissing-Jorgensen (2003), Mulligan (2004), Gruber (2006), Guvenen (2006), Hansen, Heaton, Lee, and Roussanov (2007), Engegelhardt and Kumar (2008)) argue the data supports EIS $\geq 1$. On the other hand, Hall (1988), Campbell (1999), and more recently Beeler and Campbell (2009) argue for small values of elasticity of intertemporal substitution $(E I S<1)$.
} 
I find $D v_{t}^{1} \leq 0$ for all $t .{ }^{6}$ With a higher elasticity of intertemporal substitution ( $\rho$ less than one), the future consumption stream has more immediate value and thus the value function increases. The opposite occurs when the elasticity decreases.

Assume the optimal consumption follows the stochastic volatility process of Eq. (6).

Proposition 3 In the constant volatility case, the unique solution for $v^{1}$ has a closed-form solution given by:

$$
v_{t}^{1}-c_{t}=\mu_{v}+\phi_{v} X_{t}
$$

In the stochastic volatility case, the unique solution for $v^{1}$ has a closed-form approximation given by:

$$
v_{t}^{1}-c_{t} \approx \mu_{v}+\phi_{v} X_{t}+\phi_{v, \sigma} \sigma_{t}+\phi_{v, \sigma^{2}} \sigma_{t}^{2}
$$

Proof. The details of the calculation are in appendices $\mathrm{F}$ and $\mathrm{H}$. The dependence on $\left\{X_{t}\right\}$ is exactly determined in the recursive problem of Eq. (7) and only the dependence on $\left\{\sigma_{t}\right\}$ is an approximation in Eq. (9).

My model retains most of the properties of the standard recursive utility model, but also differs from it in various important ways. I first describe the classical properties of the standard model, and then analyze the novel features due to loss aversion.

Shocks to $\left\{X_{t}\right\}$ impact next-period consumption the most (with impact $\phi_{c} \Sigma_{X} W_{t}$ ) and the impact slowly fades over time (with impact $\phi_{c} A^{\tau} \Sigma_{X} W_{t}$ after $\tau$ periods). The cumulative impact on all the future realizations of consumption is immediately reflected in the present value of the future consumption stream, the value function $V_{t}$, through the term $\phi_{v} X_{t}$ with $\phi_{v}=\beta \phi_{c} \sum_{0}^{\infty} \beta^{i} A^{i}=$ $\beta \phi_{c}(I-\beta A)^{-1}$. This dependence in the state variable $\left\{X_{t}\right\}$ is unchanged from the standard recursive utility model. The solution for $\phi_{v}$ shows (i) the log-value-to-consumption ratio is above average in good times $\left(\phi_{c} X_{t}>0\right)$ and below average in bad times $\left(\phi_{c} X_{t}<0\right)$; (ii) the higher the persistence of the consumption growth drift (the higher the module of the eigen values of $A$ ), the stronger the impact of the time varying $\left\{X_{t}\right\}$ on the value function: if the persistence is high, the value function varies more between good times and bad times, which directly translates into a higher price of risk, and thus higher expected returns for assets that covary positively with the

\footnotetext{
${ }^{6}$ The details of the calculation are given in Appendix E.
} 
consumption shocks; and (iii) increasing $\beta$ and thus the importance of the risky future consumption stream relative to immediate consumption also increases the value of $\left|\phi_{v}\right|$ and thus the price of risk.

The value function also varies with the state variable $\left\{\sigma_{t}\right\}$, which determines the volatility of the consumption process, through the parameters $\phi_{v, \sigma}$ and $\phi_{v, \sigma^{2}}$. As in the standard recursive utility model, I find $\left|\phi_{v, \sigma}\right|$ and $\left|\phi_{v, \sigma^{2}}\right|$ are increasing (i) in the rate of time discount $\beta$ (a lower rate of time discount increases the relative importance of the future consumption stream and thus the impact of its level of volatility); (ii) in the persistence of the volatility process $a$ (the higher the persistence, the more relevant the current value of $\sigma_{t}$ and thus the higher its impact on the value function); (iii) in the risk aversion coefficient $\gamma$ (a higher risk aversion increases the relative importance of the volatility); and (iv) in the volatility of the consumption process given by $\left|\Sigma_{c}\right|$, $\left|\Sigma_{X}\right|$, and $\left|\Sigma_{\sigma}\right|$ (as multipliers for the state variable $\left\{\sigma_{t}\right\}$ ).

I find the constant drift $\mu_{v}$ is (i) increasing in $\mu_{c}$ (a higher mean consumption growth translates into higher value of the consumption process); (ii) increasing in $\beta$ (a higher $\beta$, i.e, a lower time discount rate, increases the present value of the future consumption stream); (iii) decreasing in the persistence of the volatility process $a$; (iv) decreasing in the risk aversion coefficient $\gamma$ (a higher risk aversion lowers the value of the risky consumption process); and (v) decreasing in the volatility of the consumption process given by $\left|\Sigma_{c}\right|,\left|\Sigma_{X}\right|$ and $\left|\Sigma_{\sigma}\right|$ (higher risk levels lower the value of the consumption process). ${ }^{7}$

Loss aversion impacts both the constant drift $\mu_{v}$ and the parameters $\phi_{v, \sigma}$ and $\phi_{v, \sigma^{2}}$, which determine the dependence on $\left\{\sigma_{t}\right\}$, the volatility of the consumption process. In Figure $2, \mathrm{I}$ display the value of the consumption stream (relative to consumption) as it varies with volatility both in the model with loss aversion and in the standard recursive utility model. I find the value function is lower than in the standard recursive utility model, with either risk aversion $\gamma$ or risk aversion $\bar{\gamma}$, even though the agent behaves as though risk averse with risk aversion $\gamma \leq \bar{\gamma}$ on the non-disappointing outcomes. The discontinuity in risk aversion, due to the kink in the preferences, results in agents that are particularly averse to taking small risks around the reference point, and thus display an effective risk aversion that is higher than both $\gamma$, the risk aversion above the reference, and $\bar{\gamma}$, the risk aversion below the reference. This effect of loss aversion explains the low value-to-consumption ratios I obtain.

\footnotetext{
${ }^{7}$ The solutions for $\mu_{v}, \phi_{v, \sigma}$, and $\phi_{v, \sigma^{2}}$ are in appendices $\mathrm{F}$ and $\mathrm{H}$.
} 


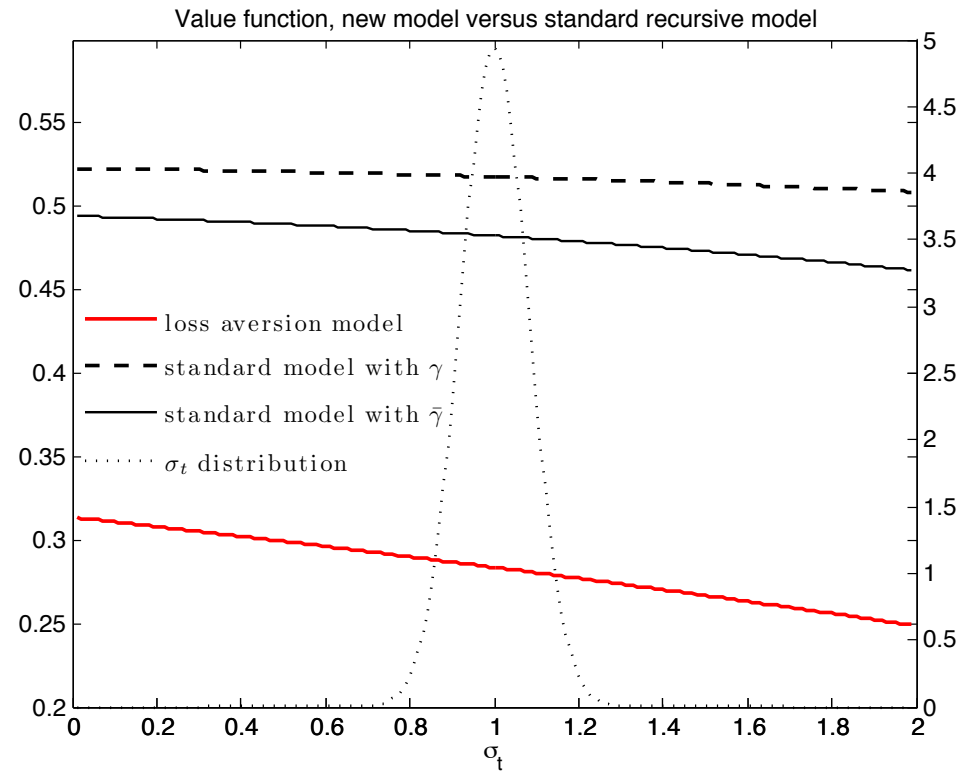

Figure 2: Value Function

$\left.\left(v_{t}-c_{t}\right)\right|_{\rho=1}$ in the model with loss aversion and in the standard recursive utility model with risk aversion $\gamma$ and $\bar{\gamma}$ are plotted on the left axis. $\bar{\gamma}$ increases with $\alpha$ as in Eq. (3): $\bar{\gamma}=\gamma+\frac{\alpha}{\alpha-1}(\gamma-1)$. Because the dependence on the state variable $\left\{X_{t}\right\}$ is the same with and without loss aversion, I plot the value functions for $X_{t}=\mathbb{E}\left(X_{t}\right)=0$. The distribution of $\sigma_{t}$ is plotted on the right axis.

I use the parameters from Hansen, Lee, Polson, and Yae (2011) for the consumption process and $\beta=0.99$, $\gamma=10, \alpha=0.55$.

I also find the value function varies more with the volatility of the consumption process in the model with loss aversion. Because the consumption volatility typically increases in bad times and decreases in good times, the pro-cyclical variations in the value function are greater in the model with loss aversion than in the standard recursive utility model.

Let us now turn to the first-order approximation around $\rho=1$.

Proposition 4 In the case with constant volatility $\left(\Sigma_{\sigma}=0\right)$, the Taylor expansion around $\rho=1$ yields:

$$
D v_{t}^{1}=\mu_{v, \rho}+\phi_{v, \rho} X_{t}+X_{t}^{\prime} \varphi_{v, \rho} X_{t}
$$

Proof. The details of the calculation are in Appendix F. ${ }^{8}$

\footnotetext{
${ }^{8} \mathrm{~A}$ similar solution could be found in the stochastic volatility case with somewhat cumbersome derivations.
} 


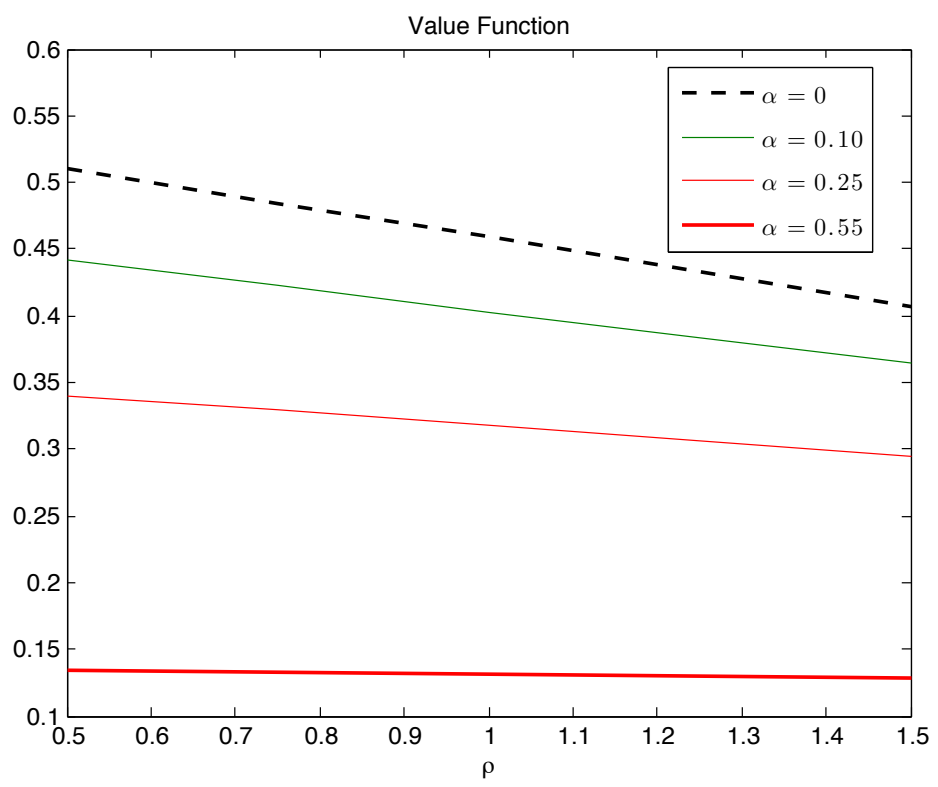

Figure 3: Value Function dependence on $\rho$

Average $v_{t}-c_{t}$ (calculated for $X_{t}=\mathbb{E}\left(X_{t}\right)=0$ ) in the model with loss aversion and in the standard recursive utility model (case $\alpha=0$ ).

I use the parameters from Hansen, Heaton, and Li (2008) for the consumption process and $\beta=0.99$, $\gamma=10$.

As mentioned above, $D v_{t}^{1} \leq 0$ for all $t$. I find $\left|D v_{t}^{1}\right|$ is higher in good times $\left(\phi_{c} X_{t} \geq 0\right)$ than in bad times $\left(\phi_{c} X_{t} \leq 0\right)$. This enhances the pro-cyclical variations of the value function when the elasticity of intertemporal substitution is greater than one $(\rho \leq 1)$ and reduces them when the elasticity of intertemporal substitution is less than one $(\rho \geq 1)$. $\left|\phi_{v, \rho}\right|$ and $\left|\mu_{v, \rho}\right|$ are lower than in the standard recursive utility model, and the solution for $\varphi_{v, \rho}$ is unchanged. Therefore, the impact of a change in the elasticity of intertemporal substitution is reduced by the loss aversion specification. In Figure 3, I display the value of the consumption stream as it varies with $\rho$. Observe that in the model with loss aversion $\alpha=0.55$, the value of the elasticity of intertemporal substitution has little impact on the value function.

I now turn to the asset pricing implications of the model. At time $t$, all uncertain returns $R_{t+1}$ must satisfy the Euler Equation:

$$
\mathbb{E}_{t}\left[R_{t+1} S_{t, t+1}\right]=1
$$

where $S_{t, t+1}$ is the stochastic discount factor between time $t$ and $t+1$. 
Proposition 5 The stochastic discount factor is given by:

$$
\begin{aligned}
S_{t, t+1}= & \beta\left(\frac{V_{t+1}}{h\left(V_{t+1}\right)}\right)^{\rho-\bar{\gamma}}\left(\frac{C_{t+1}}{C_{t}}\right)^{-\rho}\left(\overline{\frac{V_{t+1}}{V_{t+1}}}\right)^{1-\bar{\gamma}} \times \\
& \left(\left(1-\alpha \mathbf{1}_{V_{t+1} \geq \mathcal{R}_{t}\left(V_{t+1}\right)}\right)+\alpha \frac{\mathbb{E}_{t}\left(\mathbf{1}_{V_{t+1} \geq \mathcal{R}_{t}\left(V_{t+1}\right)}{\overline{V_{t+1}}}^{1-\bar{\gamma}}\right)}{\left.{\overline{V_{t+1}}}^{1-\bar{\gamma}}\right)} .\right.
\end{aligned}
$$

Proof. The details of the derivation are in Appendix D.

I analyze the solution for the stochastic discount factor above and below the reference point; For $V_{t+1} \leq \mathcal{R}_{t}\left(V_{t+1}\right)$ :

$$
S_{t, t+1}^{-}=\underbrace{\beta\left(\frac{V_{t+1}}{h\left(V_{t+1}\right)}\right)^{\rho-\bar{\gamma}}\left(\frac{C_{t+1}}{C_{t}}\right)^{-\rho}}_{\text {standard recursive utility model }}\left(1+\alpha \frac{\mathbb{E}_{t}\left(\mathbf{1}_{V_{t+1} \geq \mathcal{R}_{t}\left(V_{t+1}\right)}{\overline{V_{t+1}}}^{1-\bar{\gamma}}\right)}{\bar{V}_{t+1}-\bar{\gamma}}\right)
$$

For $V_{t+1} \geq \mathcal{R}_{t}\left(V_{t+1}\right)$ :

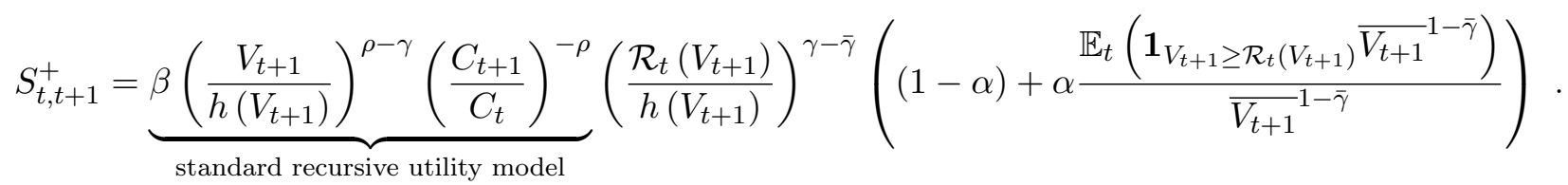

The first terms in the stochastic discount factor are those of the standard recursive utility model, with risk aversion $\bar{\gamma}$ below the reference point and risk aversion $\gamma$ above the reference point. This directly follows from the specification of loss aversion in my model of preferences. ${ }^{9}$ As in the standard recursive utility model, the covariations of cash-flows with the consumption growth and with the shocks to the value function determine prices. Shocks to all future realizations of consumption have an immediate impact on the value function. The recursive utility specification thus allows the pricing of such shocks. In contrast, in the expected utility CRRA model, the covariations with the immediate consumption shock only determine prices.

The additional terms in the stochastic discount factor are due to the incremental changes in the reference point $\mathcal{R}_{t}\left(V_{t+1}\right)$. For $V_{t+1} \leq \mathcal{R}_{t}\left(V_{t+1}\right)$, the incremental changes in the reference point increase the stochastic discount factor and thus lower the price of risk (and thus the expected returns of assets that covary positively with the consumption shocks) relative to the standard model with risk aversion $\bar{\gamma}$.

\footnotetext{
${ }^{9}$ The agent has standard preferences with risk aversion $\bar{\gamma}$ below and risk aversion $\gamma$ above the reference .
} 
At the reference point $V_{t+1}=\mathcal{R}_{t}\left(V_{t+1}\right)$, note that

$$
\frac{S_{t, t+1}^{+}}{S_{t, t+1}^{-}}=1-\alpha \frac{\mathcal{R}_{t}\left(V_{t+1}\right)}{\mathcal{R}_{t}\left(V_{t+1}\right)+\alpha \mathbb{E}_{t}\left(\mathbf{1}_{V_{t+1} \geq \mathcal{R}_{t}\left(V_{t+1}\right)}{\overline{V_{t+1}}}^{1-\bar{\gamma}}\right)} \leq 1 .
$$

When $\alpha>0$, the stochastic discount factor is discontinuous at the reference point. This is a direct consequence of the loss aversion specification, and of the kink in the preferences. The starkly different pricing effects I obtain for the model with loss aversion in section 2.2 derive from the modification of the stochastic discount factor when $\alpha>0$, in particular from the discontinuity in the stochastic discount factor at the reference point. Note that if $\alpha=0$, the stochastic discount factor of Eq. (11) reverts to the standard model with risk aversion $\gamma$.

\subsection{Risk Prices}

In this section, I compute asset prices in the model of Eq. (7) (with unit elasticity of intertemporal substitution and full updating of the reference point). I derive the expected returns and risk-price elasticities, the elasticities of expected returns with respect to the exposure to the consumption shocks, for assets with cash-flows that are correlated with the consumption process.

Consider an asset with time $t+1$ return $R_{t+1}$, which is uncertain at time $t$ and follows the conditionally log-normal process

$$
\log R_{t+1}=\left(\bar{r}_{t}-\frac{1}{2}\left|\Sigma_{R, t}\right|^{2}-\frac{1}{2}\left|\widetilde{\Sigma_{R, t}}\right|^{2}\right)+\Sigma_{R, t} W_{t+1}+\widetilde{\Sigma_{R, t}} \widetilde{W_{t+1}}
$$

where $\left\{W_{t+1}\right\}$ are the shocks to the consumption process, $\left\{\widetilde{W_{t+1}}\right\}$ are independent shocks, and $\bar{r}_{t}$ is the log expected return of the asset. ${ }^{10}$ The covariations between the log returns and the log consumption shocks and between the log returns and other independent shocks are determined by the exposure $\left(\Sigma_{R, t}, \widetilde{\Sigma_{R, t}}\right)$. I model the exposure $\left\{\Sigma_{R, t}\right\}$ as $\Sigma_{R, t}=\Sigma_{R}\left(\begin{array}{ccc}\sigma_{t} & & 0 \\ & \sigma_{t} & \\ 0 & & 1\end{array}\right)$, such that the aggregate volatility of the asset returns has same time dependence as the consumption risk.

Applying the Euler Equation of Eq. (10) and Eq. (11) to the returns of Eq. (12) yields $\bar{r}_{t}$, the $\log$ expected return, as a function of the exposure to the consumption shocks $\Sigma_{R}$ :

$$
\bar{r}_{t}\left(\Sigma_{R}\right)=-\log \mathbb{E}_{t}\left[\left(\exp \left(\Sigma_{R, t} W_{t+1}-\frac{1}{2}\left|\Sigma_{R, t}\right|^{2}\right)\right) S_{t, t+1}\right]
$$

\footnotetext{
${ }^{10}$ I choose to model the returns directly as log-normal to obtain closed-form solutions on the expected returns and risk-price elasticities as functions of the exposure to the consumption shocks. Another choice would be to model the asset's cash-flows, rather than the returns, as log-normal. Such a modeling choice would generate returns with close to log-normal distributions and would yield numerical results in line with the closed-form solutions of my model.
} 
Increasing the exposure of the log returns to the log-consumption shocks, $\Sigma_{R}$, has a price, which is reflected in a change in $\bar{r}_{t}$, the log expected returns. The risk-price elasticities measure such changes. For a given exposure to the consumption shocks, $\Sigma_{R}$, the risk-price elasticity is given by $R P_{t}\left(\Sigma_{R}\right)$ with:

$$
R P_{t}\left(\Sigma_{R}\right)=\frac{\partial \bar{r}_{t}\left(\Sigma_{R}\right)}{\partial \Sigma_{R}}
$$

\section{Risk-Free Rate}

Consider the risk-free asset, $\bar{r}_{t}(0)=r f_{t}{ }^{11}$ To analyze the impact of the loss aversion specification, I start with the constant-volatility case. As a second-order approximation around $\phi_{v} \Sigma_{X}=0$, and $\Sigma_{c}=0:^{12}$

$$
\begin{aligned}
r f_{t}^{1} \approx- & -\log \beta+\mu_{c}+\phi_{c} X_{t}-\frac{1}{2}\left|\Sigma_{c}\right|^{2}+(1-\gamma)\left(\Sigma_{c}+\phi_{v} \Sigma_{X}\right) \Sigma_{c}^{\prime} \\
-\alpha & \underbrace{\left\{\begin{array}{l}
\frac{1}{\sqrt{2 \pi}} \frac{\Sigma_{c}\left(\Sigma_{c}+\phi_{v} \Sigma_{X}\right)^{\prime}}{\left|\Sigma_{c}+\phi_{v} \Sigma_{X}\right|}\left(1-\frac{1}{2 \sqrt{2 \pi}} \alpha \frac{\Sigma_{c}\left(\Sigma_{c}+\phi_{v} \Sigma_{X}\right)^{\prime}}{\left|\Sigma_{c}+\phi_{v} \Sigma_{X}\right|}\right) \\
+\frac{1}{2} \alpha\left(1-\frac{1}{\pi}\right)(\bar{\gamma}-1)\left(\Sigma_{c}+\phi_{v} \Sigma_{X}\right) \Sigma_{c}^{\prime}
\end{array}\right.}_{\text {loss aversion terms }} .
\end{aligned}
$$

The first terms are those of the standard recursive utility model and the usual comparative statics obtain. The risk-free rate is (i) pro-cyclical through $\phi_{c} X_{t}$; (ii) increasing in the mean consumption growth $\mu_{c}$ (when the expected consumption growth is high, agents are less inclined to save); (iii) decreasing in $\beta$ (with a lower rate of time discount, the agents are more willing to substitute between immediate and future consumption and thus to save); and (iv) decreasing in the risk aversion $\gamma$ and in the amount of risk determined by $\left|\Sigma_{c}\right|$ and $\left|\phi_{v} \Sigma_{X}\right|$, through the precautionary savings term $(1-\gamma)\left(\Sigma_{c}+\phi_{v} \Sigma_{X}\right) \Sigma_{c}^{\prime}$.

Loss aversion results in additional precautionary savings terms that lower the risk-free rate and amplify its sensitivity to the risk aversion $\gamma$ and to the amount of risk in the consumption process. Observe that the precautionary savings due to loss aversion dominate over the usual precautionary savings term: the discontinuity in the stochastic discount factor results in the only first-order term, $\frac{\alpha}{\sqrt{2 \pi}} \frac{\Sigma_{c}\left(\Sigma_{c}+\phi_{v} \Sigma_{X}\right)^{\prime}}{\left|\Sigma_{c}+\phi_{v} \Sigma_{X}\right|}$, in the risk-free rate of Eq. (15) with $\phi_{v} \Sigma_{X} \approx 0$ and $\Sigma_{c} \approx 0$.

The impact of loss aversion on the risk-free rate is displayed in Figure 4. Due to the discontinuity in the stochastic discount factor at the reference point, and its consequent first-order

\footnotetext{
${ }^{11}$ The closed-form solutions for the risk-free rate are provided in Appendix F for the constant volatility case and Appendix $\mathrm{H}$ for the general case.

${ }^{12}$ Because the consumption growth is a low volatility process, this approximation is justified.
} 


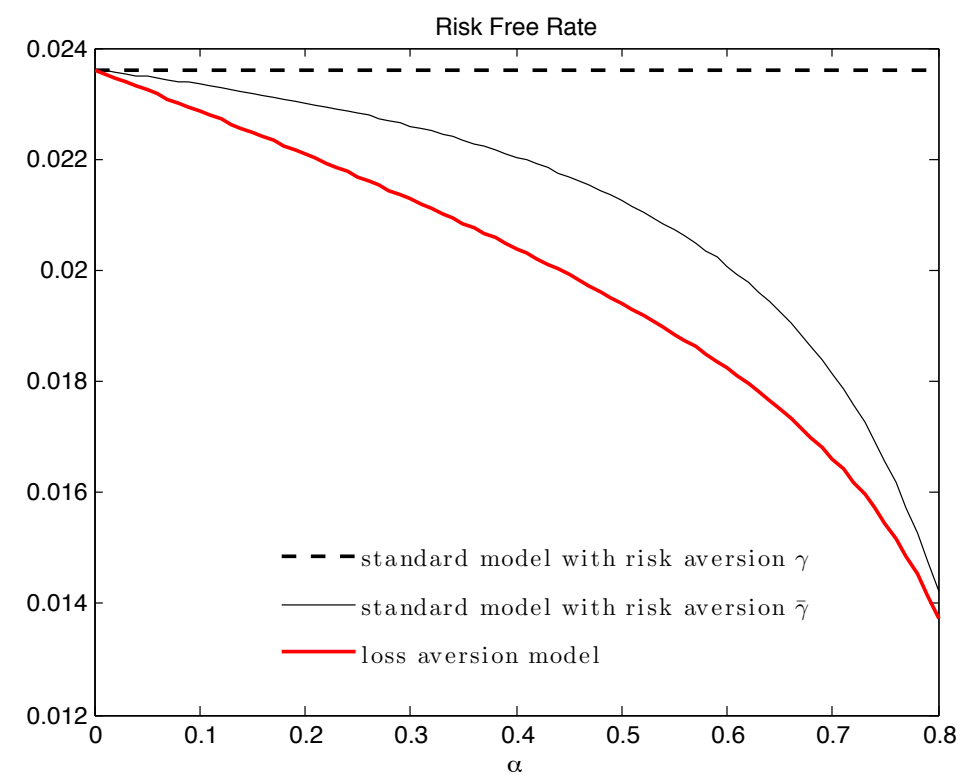

Figure 4: Risk-Free Rate

The annual risk-free rates with and without loss aversion (standard recursive utility model with risk aversions $\gamma$ and $\bar{\gamma}$ ) are plotted as functions of the coefficient of loss aversion $\alpha . \bar{\gamma}$ increases with $\alpha$ as in Eq. (3): $\bar{\gamma}=\gamma+\frac{\alpha}{\alpha-1}(\gamma-1)$. Because the dependence on the state variable $\left\{X_{t}\right\}$ is the same with and without loss aversion, I plot the risk-free rates for $X_{t}=\mathbb{E}\left(X_{t}\right)=0$.

I use the parameters from Hansen, Heaton, and $\mathrm{Li}$ (2008) for the consumption process and $\beta=0.999$, $\gamma=10$.

risk aversion, observe that the risk-free rate in the model with loss aversion is lower than in the standard recursive utility model, with either risk aversion $\gamma$ or high risk aversion $\bar{\gamma}$. The standard recursive utility model tends to overvalue the risk-free rate. As a result, the model with loss aversion improves on the calibration of the risk-free rate, even when compared to the standard recursive utility model with high risk aversion $\bar{\gamma}$.

These results extend to the stochastic volatility case $\left(\Sigma_{\sigma} \neq 0\right)$. I plot in Figure 5 the annual risk-free rate as a function of the volatility $\sigma_{t}$. The risk-free rate's dependence on $\left\{\sigma_{t}\right\}$, the state variable governing the volatility of consumption, is greater in the model with loss aversion. Because the volatility of the consumption growth process typically increases following a downturn, the risk-free rate is more strongly pro-cyclical in the model with loss aversion than in the standard recursive utility model. 


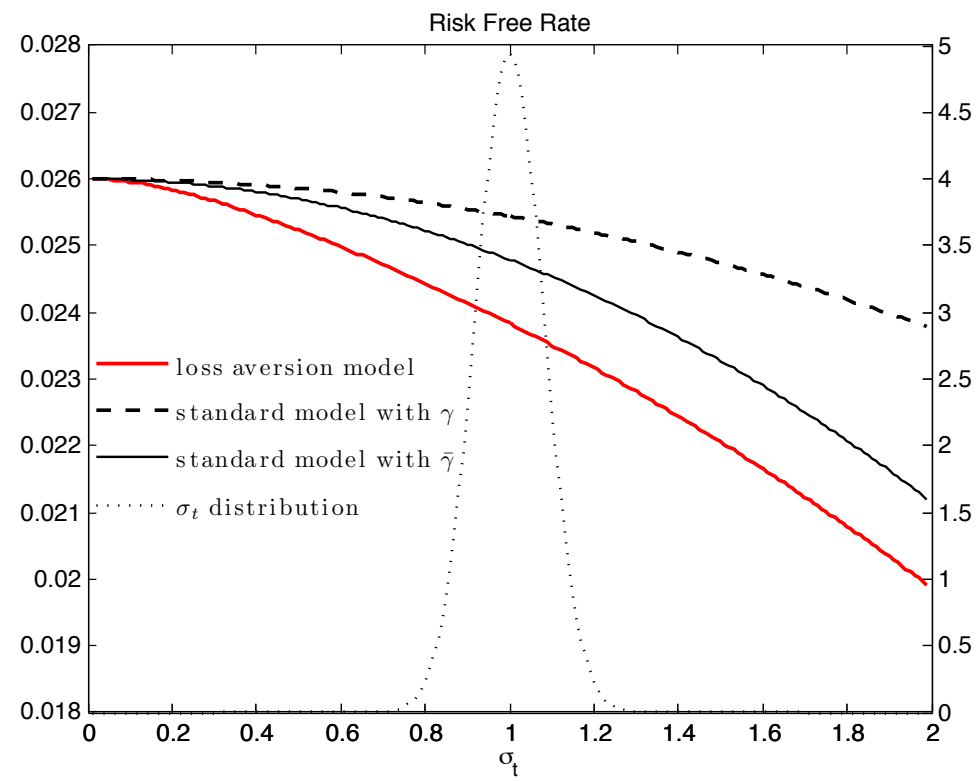

Figure 5: Risk-Free Rate

The annual risk-free rate with and without loss aversion (standard recursive utility model for risk aversion $\gamma$ and $\bar{\gamma}$ ) are plotted on the left axis. $\bar{\gamma}$ increases with $\alpha$ as in Eq. (3): $\bar{\gamma}=\gamma+\frac{\alpha}{\alpha-1}(\gamma-1)$. Because the dependence on the state variable $\left\{X_{t}\right\}$ is the same with and without loss aversion, I plot the risk-free rates for $X_{t}=\mathbb{E}\left(X_{t}\right)=0$. On the right axis, I plot the distribution of $\sigma_{t}$.

I use the parameters from Hansen, Lee, Polson, and Yae (2011) for the consumption process and $\beta=0.999$, $\gamma=10, \alpha=0.55$. 


\section{Expected Excess Returns}

I now turn to the pricing of assets that covary with the consumption shocks $\left(\Sigma_{R} \neq 0\right){ }^{13}$ I start with the constant-volatility case, and, in Figure 6, I display the expected excess returns $\left\{\bar{r}_{t}\left(\Sigma_{R}\right)-r f_{t}\right\}$ and risk-price elasticities $\left\{R P_{t}\left(\Sigma_{R}\right)\right\}$ of assets that vary in their exposures to the immediate consumption shock. ${ }^{14}$

These graphs illustrate the fundamental differences for asset pricing between the model with loss aversion and the standard recursive utility model.

First, for assets with positive exposure to the shocks, the risk-price elasticities decrease sharply between small exposures and large exposures to the consumption shocks.

Second, the expected excess returns for assets that covary positively with the consumption shocks are increased by the loss aversion specification, especially for assets with low exposure to the shocks, such as the market portfolio.

The discontinuity in risk aversion results in agents that are particularly averse to taking small risks around the reference point, thus explaining both the cross-sectional result and the level effect for asset prices.

Third, the risk-price elasticities are higher for negative exposure to the consumption shocks (hedges) than for positive ones. Hedges generate positive returns when the shocks are negative and the agent is disappointed, and are thus mostly priced in a model with high risk aversion $\bar{\gamma} \geq \gamma$. In contrast, assets with positive exposure to the consumption shocks generate positive returns when the agent is not disappointed, and are thus mostly priced in a model with risk aversion $\gamma$, thereby resulting in lower risk-price elasticities. This feature would extend to option prices, with higher implied volatilities on the put options than on the call options.

\footnotetext{
${ }^{13}$ The closed-form solutions for the returns and risk-price elasticities are in Appendix F for the constant volatility case and in Appendix $\mathrm{H}$ for the general case.

${ }^{14}$ The graphs display the same characteristic shapes for assets that vary in their exposures to the second shock. They are provided in Figure 13 in Appendix F.
} 

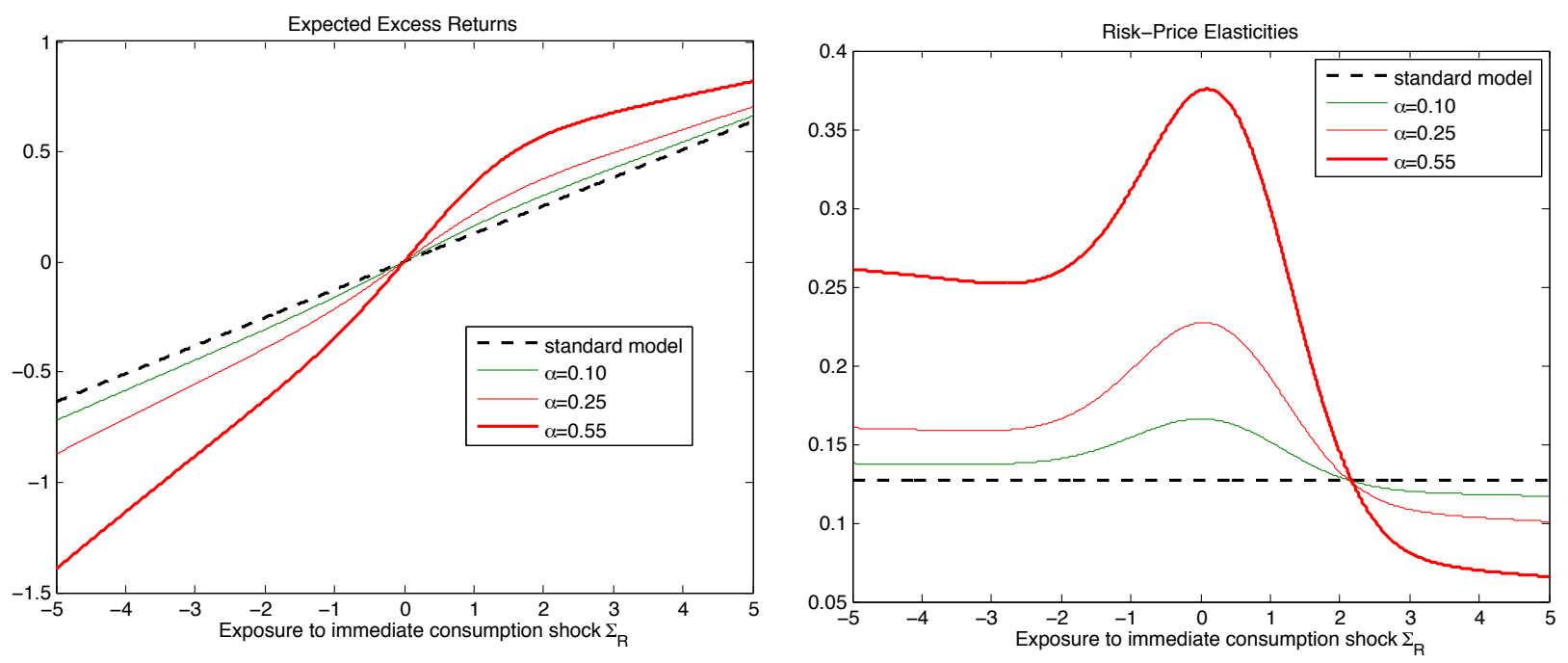

Figure 6: Asset Prices with Constant Volatility

The two graphs display the expected excess returns and the risk-price elasticities for assets with exposure to the immediate consumption shock $\left[\begin{array}{cc}\Sigma_{R} & 0\end{array}\right] W_{t+1}$ in the model with constant volatility, for various values of $\alpha$, the coefficient of loss aversion. The case $\alpha=0$ reverts to the standard recursive utility model. I use the parameters from Hansen, Heaton, and $\mathrm{Li}$ (2008) for the consumption process and $\beta=0.999$, $\gamma=10$.

To better understand how these effects arise, I analyze the behavior of the expected excess returns at the asymptotes $\left(\left|\Sigma_{R}\right| \longrightarrow+\infty\right)$ and around zero.

When $\left|\Sigma_{R}\right| \gg\left|\Sigma_{c}\right|$, and $\left|\Sigma_{R}\right| \gg\left|\phi_{v} \Sigma_{X}\right|$, I obtain the approximation:

$$
\begin{aligned}
\bar{r}_{t}\left(\Sigma_{R}\right)-r f_{t} & \approx_{\left|\Sigma_{R}\right| \longrightarrow+\infty}\left(\gamma \Sigma_{c}+(\gamma-1) \phi_{v} \Sigma_{X}\right) \Sigma_{R}^{\prime} \\
& \underbrace{\log \left[\begin{array}{l}
\Phi\left(-\frac{\left(\phi_{v} \Sigma_{X}+\Sigma_{c}\right) \Sigma_{R}^{\prime}}{\left|\left(\phi_{v} \Sigma_{X}+\Sigma_{c}\right)\right|}\right) \exp \left(-\alpha(\bar{\gamma}-1)\left(\phi_{v} \Sigma_{X}+\Sigma_{c}\right) \Sigma_{R}^{\prime}\right) \\
+\alpha \Phi\left(-(\gamma-1)\left|\phi_{v} \Sigma_{X}+\Sigma_{c}\right|\right) \exp \left((\gamma-1)\left(\phi_{v} \Sigma_{X}+\Sigma_{c}\right) \Sigma_{R}^{\prime}\right)
\end{array}\right]}_{\text {loss aversion term }} .
\end{aligned}
$$

The first term in Eq. (16) is unchanged from the standard recursive utility model. The riskprice elasticities of the standard model are constant and equal to $\gamma \Sigma_{c}+(\gamma-1) \phi_{v} \Sigma_{X}$. The first term, $\gamma \Sigma_{c}$, is identical to the expected utility CRRA model with risk aversion $\gamma$. The additional term, $(\gamma-1) \phi_{v} \Sigma_{X}$, comes from the recursive specification. Shocks to the state variable $\left\{X_{t}\right\}$ impact all future realizations of consumption. This is reflected, with the multiplier $\phi_{v}$, as a shock to the value function, and thus covariations with this shock are priced in the expected excess returns. Through these two channels (immediate consumption shock and shock to the value function), the expected excess returns are increasing in the coefficient of risk aversion $\gamma$, in the level of risk (given by $\left|\Sigma_{c}\right|$ and $\left|\Sigma_{X}\right|$ ), in the persistence of the consumption process, and in $\beta$. 
The extra term due to loss aversion introduces important non-linearities in the relation between the log expected returns and the log exposure to consumption shocks. I analyze its impact on both asymptotes.

When $\left(\phi_{v} \Sigma_{X}+\Sigma_{c}\right) \Sigma_{R}^{\prime} \rightarrow+\infty$, I find $\bar{r}_{t}\left(\Sigma_{R}\right)-r f_{t} \sim \Sigma_{c} \Sigma_{R}^{\prime}$. The risk-price elasticity tends towards $\Sigma_{c}$, and thus towards lower values, for both the immediate consumption shock and the long-run consumption shock, than in the standard recursive utility model with risk aversion $\gamma \cdot{ }^{15}$ Remember from Eq. (2) that above the reference point, the agent behaves as in the standard model with risk aversion $\gamma$, with a scaling factor that depends on the value of the reference point. The direct contribution to the value function of the reference point (see Appendix A) dominates when the agent is far and above the disappointment threshold. The log-normal model for the reference point incurs a risk-price elasticity equal to $\Sigma_{c}$, as in the expected utility CRRA model with unit risk aversion.

Below the reference point, the agent behaves as in the standard model with risk aversion $\bar{\gamma}$ and, accordingly, I find $\bar{r}_{t}\left(\Sigma_{R}\right)-r f_{t} \sim\left(\bar{\gamma} \Sigma_{c}+(\bar{\gamma}-1) \phi_{v} \Sigma_{X}\right) \Sigma_{R}^{\prime}$ when $\left(\phi_{v} \Sigma_{X}+\Sigma_{c}\right) \Sigma_{R}^{\prime} \rightarrow-\infty$.

I now turn to the behavior of the expected excess returns when the exposure to the consumption shocks is close to zero. For $\left|\Sigma_{R}\right| \longrightarrow 0$, a second-order approximation around $\phi_{v} \Sigma_{X}=0$ and $\Sigma_{c}=0$ simplifies the solution for the expected excess returns to:

$$
\begin{aligned}
\bar{r}_{t}\left(\Sigma_{R}\right)-r f_{t} & \approx_{\left|\Sigma_{R}\right| \approx 0}\left(\gamma \Sigma_{c}+(\gamma-1) \phi_{v} \Sigma_{X}\right) \Sigma_{R}^{\prime} \\
& \underbrace{+\alpha\left[\begin{array}{l}
\frac{1}{\sqrt{2 \pi}} \frac{\Sigma_{R}\left(\phi_{v} \Sigma_{X}+\Sigma_{c}\right)^{\prime}}{\left|\phi_{v} \Sigma_{X}+\Sigma_{c}\right|}\left(1-\frac{\alpha}{\sqrt{2 \pi}} \frac{\Sigma_{c}\left(\phi_{v} \Sigma_{X}+\Sigma_{c}\right)^{\prime}}{\left|\phi_{v} \Sigma_{X}+\Sigma_{c}\right|}\right) \\
+\frac{1}{2} \alpha(\bar{\gamma}-1)\left(1-\frac{1}{\pi}\right) \Sigma_{R}\left(\phi_{v} \Sigma_{X}+\Sigma_{c}\right)^{\prime}+\frac{1}{4 \pi} \alpha\left(\frac{\Sigma_{R}\left(\phi_{v} \Sigma_{X}+\Sigma_{c}\right)^{\prime}}{\left|\phi_{v} \Sigma_{X}+\Sigma_{c}\right|}\right)^{2}
\end{array}\right]}_{\text {loss aversion terms }} .
\end{aligned}
$$

The additional terms due to loss aversion have positive loadings on $\Sigma_{R}$ and thus push the riskprice elasticities above those of the standard recursive utility model. Further, for $\left|\Sigma_{c}\right|,\left|\phi_{v} \Sigma_{X}\right|$, and $\left|\Sigma_{R}\right|$ close to zero, the only first-order term, $\frac{\alpha}{\sqrt{2 \pi}} \frac{\Sigma_{R}\left(\phi_{v} \Sigma_{X}+\Sigma_{c}\right)^{\prime}}{\left|\phi_{v} \Sigma_{X}+\Sigma_{c}\right|}$, obtains through the loss aversion specification, and its subsequent discontinuity in the stochastic discount factor at the reference point. Notice this term does not depend on the risk aversion $\gamma$ nor on the volatility $\left|\phi_{v} \Sigma_{X}+\Sigma_{c}\right|$. As a consequence, the contribution of the loss aversion specification to the expected excess returns is significant, even for small values of $\alpha$, the coefficient of loss aversion, and this effect is particularly true for low consumption volatility and low levels of risk aversion. For reasonably low levels of risk

\footnotetext{
${ }^{15}$ In Hansen, Heaton, and Li (2008), as in Bansal and Yaron (2004), $\Sigma_{c}$ and $\Sigma_{X}$ load positively on both shocks and thus their impacts on the risk-price elasticities complement rather than offset each other.
} 
aversion, this results in the hump shape of Figure 6: the risk-price elasticities for small exposures to the consumption shocks are above both asymptotes. ${ }^{16}$ In particular, they are above the riskprice elasticities of the standard recursive utility model with risk aversion $\bar{\gamma}$. The model with loss aversion generates expected excess returns for assets with relatively small exposures to the consumption shocks (such as the market portfolio) that are above those of the standard recursive utility model, even with high risk aversion $\bar{\gamma}$.

In figures 7 and 8, I display the risk-price elasticities in the stochastic volatility case, for assets that vary in their exposures to the immediate consumption shock, and assets that vary in their exposures to the volatility shock, as functions of the exposure to the shocks and of the volatility of the underlying consumption process. ${ }^{17}$

Observe that the results derived in the constant volatility model extend to the model with stochastic volatility. The risk-price elasticities display asymmetrical bell shapes and both a level effect and a cross-sectional effect obtain. ${ }^{18}$

Notice in both figures that, as the volatility of consumption increases, the level effect due to loss aversion decreases. Indeed, increasing the volatility of the consumption process reduces the probability that assets are priced around the kink in the preferences, and thus reduces the level impact of loss aversion on the risk-price elasticities.

For assets that vary in their exposures to the consumption shocks, as in Figure 7, note that, as the volatility of the consumption process increases, so does the bell shape in the risk-price elasticities. When the volatility is so low that the consumption process is essentially always at the kink, only assets with extreme exposure to the consumption shocks start to display a decrease in their risk-price elasticities. In contrast, when the consumption process is volatile, assets are more likely to be priced away from the kink in the preferences and the bell shape is more pronounced. As a consequence, for the risk-price elasticities on the consumption shocks, increases in the volatility of the consumption process (i) reduce the level effect; and (ii) enhance the cross-sectional effect.

Observe further that, for small exposures to the consumption shocks, the risk-price elasticities increase with $\sigma_{t}$ at a faster rate in the model with loss aversion than in the standard recursive

\footnotetext{
${ }^{16}$ Using the parameters of Hansen, Heaton, and Li (2008) for the aggregate consumption, the hump-shape persists for risk aversion coefficients up to $\gamma=25$.

${ }^{17}$ The graphs display the same characteristic shapes for assets that vary in their exposures to the second consumption shock. They are provided in Figure 15 in Appendix H.

${ }^{18}$ The risk-price elasticities are negative and the asymmetry is reversed, with a higher right-hand side asymptote, for the volatility shocks, which impact the value function negatively.
} 
utility model. Because the volatility of the consumption growth typically increases following a downturn, the risk-price elasticities for the consumption shocks are more strongly counter-cyclical in my model with loss aversion.

In contrast, for assets that vary in their exposures to the volatility shocks, as in Figure 8, note that, as the volatility of the consumption process increases, the bell shape in the risk-price elasticities decreases. When the volatility is very low, assets with small exposures to the volatility risk are priced close to the kink in the preferences and thus yield high risk-price elasticities. In contrast, assets with large exposures to volatility risk are priced far from the kink and thus yield lower risk-price elasticities. When the volatility is high, on the other hand, the expected returns for both small and large exposures to the volatility shocks are determined in a large range around the kink, thus yielding similar risk-price elasticities for all assets. For the risk-price elasticities on the volatility shocks, increases in the volatility of the consumption process (i) reduce the level effect; and (ii) reduce the cross-sectional effect.

Depending on the risk aversion coefficient, this contrasting effect is strong enough to generate risk-price elasticities that are decreasing in the volatility of the consumption process, for assets with small exposures to the volatility shocks. For $\gamma \leq 20$, my loss aversion model results in riskprice elasticities for the volatility shocks that are pro-cyclical, for assets with small exposures to the shocks, and counter-cyclical for assets with large exposures to the shocks. These interesting predictions of my model can be contrasted to those of the standard recursive utility model, in which the risk-price elasticities are counter-cyclical for all the shocks. Exploring their empirical application is left for future research. 

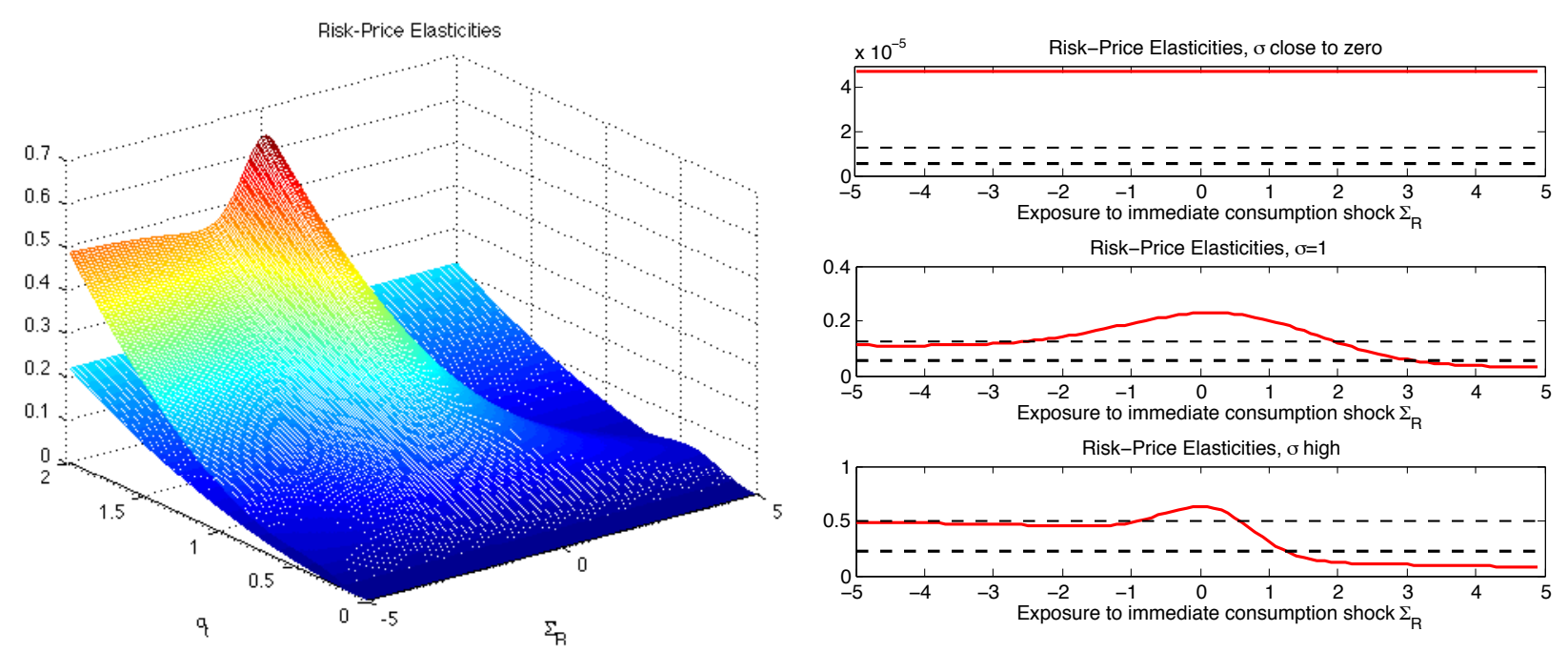

Risk-Price Elasticities, $\sigma$ high

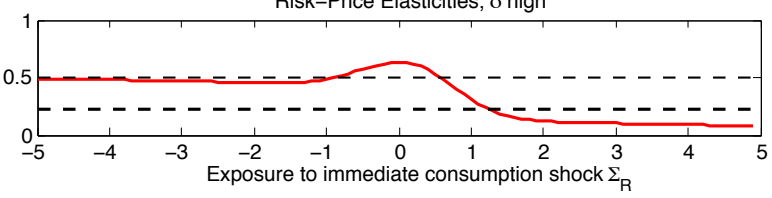

Figure 7: Asset Prices with Time-varying Volatility- Immediate Consumption Shock The two graphs display the risk-price elasticities for an exposure $\left[\begin{array}{ccc}\sigma_{t} \Sigma_{R} & 0 & 0\end{array}\right] W_{t+1}$, for the loss aversion model with loss aversion $\alpha=0.55$ and the standard recursive utility model with risk aversion $\gamma$ (the plane in the first graph and the lower dotted line in the second graph) and $\bar{\gamma}$ (the higher dotted line in the second graph). $\bar{\gamma}$ increases with $\alpha$ as in Eq. (3): $\bar{\gamma}=\gamma+\frac{\alpha}{\alpha-1}(\gamma-1)$. The second graph displays the three cases, $\sigma_{t} \approx 0, \sigma_{t}=1$ (mean value), and $\sigma_{t}=2$.

I use the parameters from Hansen, Lee, Polson, and Yae (2011) for the consumption process and $\beta=0.999$, $\gamma=10, \alpha=0.55$.
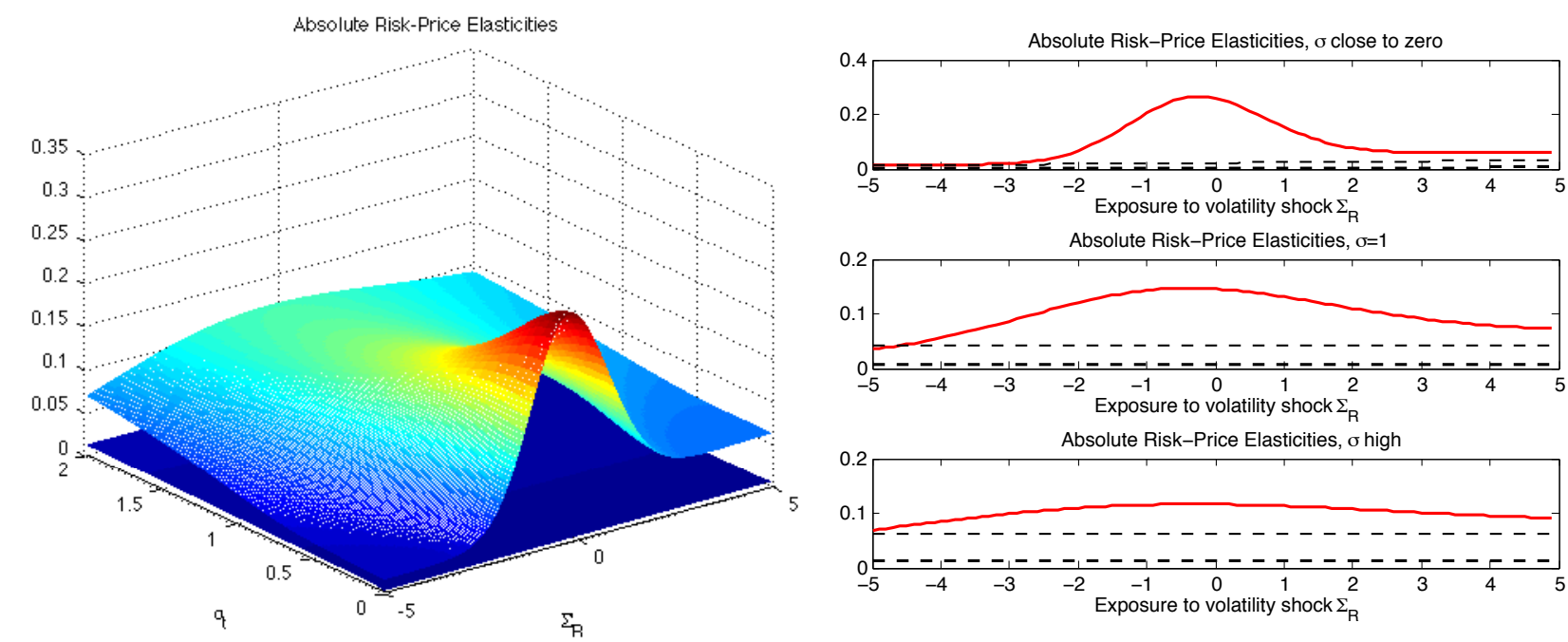

Figure 8: Asset Prices with Time-varying Volatility- Volatility Shock

The two graphs display the absolute value of the risk-price elasticities for an exposure $\left[\begin{array}{ccc}0 & 0 & \Sigma_{R}\end{array}\right] W_{t+1}$ (or $-R P_{t}\left(\left[\begin{array}{ccc}0 & 0 & \Sigma_{R}\end{array}\right]\right)$ ), for the loss aversion model with loss aversion $\alpha=0.55$ and the standard recursive utility model with risk aversion $\gamma$ (the plane in the 1st graph and the lower dotted line in the second graph) and $\bar{\gamma}$ (the higher dotted line in the $2 \mathrm{~d}$ graph). $\bar{\gamma}$ increases with $\alpha$ as in Eq. (3): $\bar{\gamma}=\gamma+\frac{\alpha}{\alpha-1}(\gamma-1)$. The second graph displays the three cases, $\sigma_{t} \approx 0, \sigma_{t}=1$ (mean value), and $\sigma_{t}=2$. I use the parameters from Hansen, Lee, Polson, and Yae (2011) for the consumption process and $\beta=0.999$, $\gamma=10, \alpha=0.55$. 


\subsection{History Dependence in the Updating of the Reference Point}

I now consider the model with history dependence in the updating of the reference point. The reference point is given by the model of Eq. (4), and I consider the simple case in which the reference point at time $t$ depends on expectations at times $t$ and $t-1$ only $(T=1)$, which simplifies the derivations of the solutions to the model while still allowing an analysis of the time variations induced by the history dependent reference point. I restrict the analysis to the constant consumption volatility case, which allows me to disentangle the time variations due to the history dependence in the reference point from those due to time-varying consumption volatilities, and I solve the model with unit intertemporal elasticity of substitution $(E I S=1)$.

The present value of the future consumption stream is the unique solution to the recursive problem given by:

$$
\begin{aligned}
v_{t}^{1} & =(1-\beta) c_{t}+\frac{\beta}{1-\bar{\gamma}} \log \mathbb{E}_{t}\left[\exp (1-\bar{\gamma}) \overline{v_{t+1}^{1}}\right] \\
\overline{v_{t+1}^{1}} & =v_{t+1}^{1}-\alpha \max \left(0, v_{t+1}^{1}-\widetilde{\mathbb{E}}_{\xi, t}\left(v_{t+1}^{1}\right)\right) \\
\widetilde{\mathbb{E}}_{\xi, t}\left(v_{t+1}^{1}\right) & =\frac{\mathbb{E}_{t}\left(v_{t+1}^{1}\right)+\xi \mathbb{E}_{t-1}\left(v_{t+1}^{1}\right)}{1+\xi} .
\end{aligned}
$$

Proposition 6 The unique solution for $v^{1}$ is given by:

$$
v_{t}^{1}-c_{t}=\mu_{v, s}+\phi_{v} X_{t}+f\left(\frac{\xi}{1+\xi} \Sigma_{s} W_{t}\right)
$$

where $\phi_{v}$ and $\Sigma_{s}$ are determined by the parameters of the consumption process, independent from $\xi$, and $f$ has the following properties:

1) $f$ is decreasing

2) $f(0)=0$

3) $f$ converges to a constant in $-\infty$

4) $f(x) \sim_{+\infty}-\alpha \beta x$.

Proof. The details of the calculation are in Appendix G.

Through its dependence in the consumption shocks $W_{t}, v_{t}^{1}-c_{t}$ depends not only on $X_{t}$, the realization of the state variable at time $t$, but also on $X_{t-1}$, the realization of the state variable at time $t-1$. The history-dependent reference point thus results in a history-dependent value function. 
The shocks to consumption $W_{t}$ affect the value function $v_{t}^{1}$ through two channels: $\phi_{v} X_{t}$ and $f\left(\frac{\xi}{1+\xi} \Sigma_{s} W_{t}\right)$, where the negative impact of the decreasing function $f$ is counterbalanced by the positive impact of $\phi_{v} X_{t}$. Indeed, the value function of Eq. (19) can be rewritten as $v_{t}^{1}-c_{t-1}=$ $g\left(X_{t-1}, W_{t}\right)$, with $g$ increasing in both $X_{t-1}$ and $W_{t} \cdot{ }^{19}$ This is a more intuitive model of the value function and it shows that the value of the future consumption stream increases following positive shocks to consumption.

I now turn to the asset pricing implications of the model with history dependence in the reference point. As before, I consider assets with log-normal distributions, as in Eq. (12). In contrast to the model of section 2.1, with full updating of the reference point, both the risk-free rate and the expected excess returns are now time varying, through their dependence in the shocks between $t-1$ and $t .^{20}$ In Figure 9, I display the expected excess returns, as well as the risk-free rate, as they vary with the past shocks.

As in the standard model, the risk-free rate varies with $\phi_{c} X_{t}$, and these pro-cyclical variations dominate over the direct impact of the shocks $W_{t}$ : the risk-free rate can be written as $g_{r_{f}}\left(X_{t-1}, W_{t}\right)$, where $g_{r_{f}}$ is increasing in both terms. ${ }^{21}$ However, if $X_{t}=0$, I find the risk-free rate is at a local minimum when $W_{t}=0$. Remember from the analysis of section 2.2 that the impact of loss aversion on asset prices is strongest when outcomes are close to the reference point. Strictly positive and strictly negative shocks to consumption $\left(W_{t} \neq 0\right)$, both decrease the probability of being close to the reference point, and thus diminish the impact of loss aversion, which justifies the risk-free rate's local minimum at $W_{t}=0$.

The expected excess returns are decreasing around $W_{t}=0$. Following negative shocks to consumption, the probability of disappointment increases thus resulting in higher risk-price elasticities, and the opposite effect arises following positive shocks. The model with history dependence in the reference point thus yields mostly counter-cyclical expected excess returns, as observed in the data. However, observe that unusually large and negative past shocks to consumption, more than two standard deviations below zero, actually result in lower, and not higher, expected excess returns. Large past consumption shocks between $t-1$ and $t$ decrease the probability of outcomes at time $t+1$ that are close to the reference point $r_{t}$, which diminishes the impact of loss aversion and thus reduces the risk-price elasticities. For large negative shocks, this effect dominates over

\footnotetext{
${ }^{19}$ Proof is given in Appendix G.

${ }^{20}$ Details of the calculations are in Appendix G.

${ }^{21}$ See Appendix G.
} 

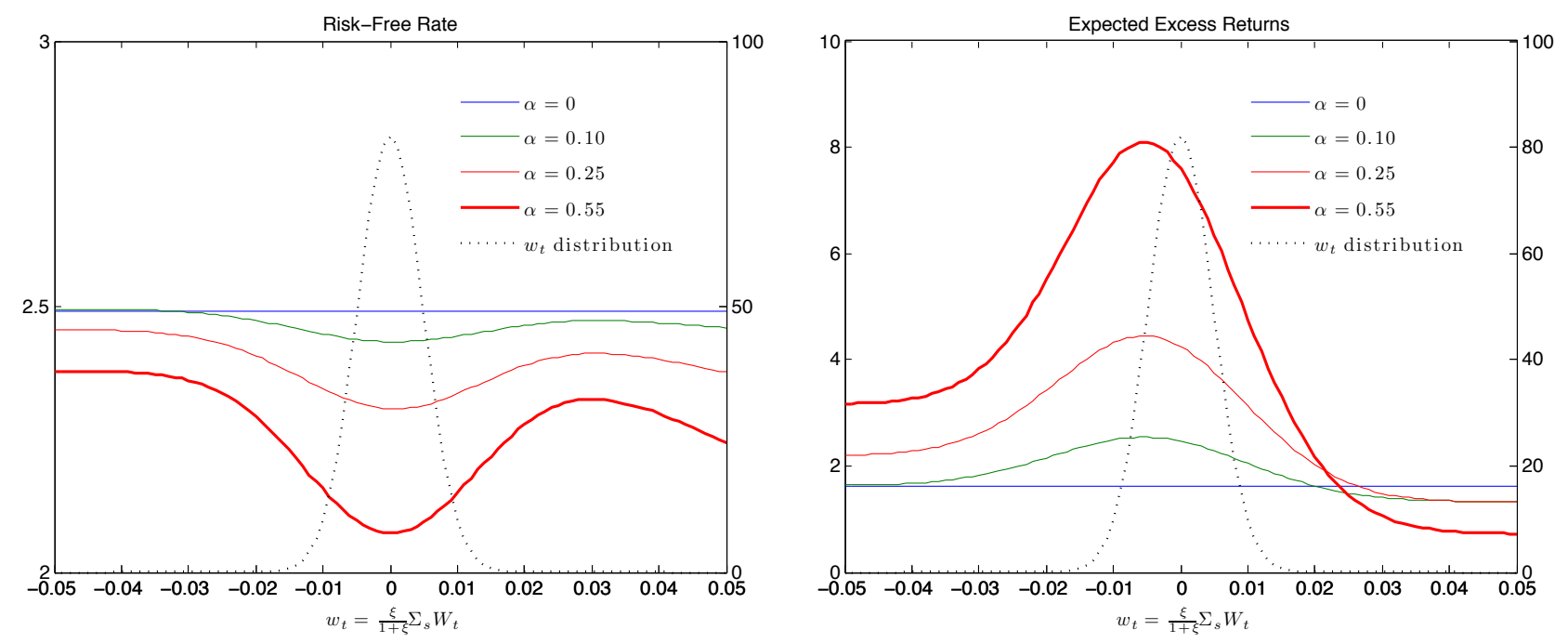

Figure 9: Asset Prices: History-dependent Reference Point

The two graphs display the annual (in \%) risk-free rate and the expected excess returns of an asset with same characteristics (volatility and skewness) as the market portfolio, for various values of $\alpha$, the coefficient of loss aversion (the case $\alpha=0$ reverts to the standard recursive utility model), as functions of the past shock $w_{t}=\frac{\xi}{1+\xi} \Sigma_{s} W_{t}$. For the risk-free rate, I assume $X_{t}=\mathbb{E}\left(X_{t}\right)=0$.

I use the parameters from Hansen, Heaton, and $\mathrm{Li}$ (2008) for the consumption process and $\beta=0.999$, $\gamma=5, \xi=0.5$. Other values of $\xi$ yield similar asset pricing results.

the increase in the probability of disappointment, thus resulting in lower expected excess returns. This effect of loss aversion generates predictions for the expected excess returns that differ from those of other models of history dependent preferences, such as the habit formation model. The analysis of empirical evidence regarding such effects is left for future research.

\section{Empirics}

In this section, I bring my model to the data and find strong support for the recursive utility model with loss aversion. In section 3.1, I evaluate the risk-free rate, the value premium, and the equity premium using my model with loss aversion. I find my model improves on the calibration of the standard recursive utility model with both risk aversion $\gamma$ and high risk aversion $\bar{\gamma}$. In sections 3.2 and 3.3, I show how the cross-sectional effect of the model with loss aversion can offer a novel theoretical justification for two important results of the empirical finance literature: the negative premium for skewness and the security market line (the excess returns as a function of beta, the exposure to market risk) flatter than the CAPM. 


\subsection{Asset Returns}

To quantitatively analyze the asset returns in the model with loss aversion, I consider the constant volatility case $\left(\Sigma_{\sigma}=0\right)$ and use the results of Hansen, Heaton, and Li (2008). In Hansen, Heaton and $\mathrm{Li}$ (2008), the state variable $\left\{X_{t}\right\}$ is explicitly determined by two macro variables: the consumption growth and the earnings-to-consumption ratio where earnings and consumption are assumed to be cointegrated. Both variables have quarterly time series (1947 to 2010) taken from the National Income and Product Accounts (NIPA). Consumption is the seasonally adjusted aggregate consumption of non-durables and services. Corporate earnings are converted to real terms using the implicit price deflator for non-durables and services. The loadings on the shocks $\left\{W_{t}\right\}$ of any dividend process are obtained directly from the macro data. They are not influenced by the modeling choice for preferences and can therefore be used to contrast the implications for asset returns of the standard recursive utility model and those of the model with loss aversion. ${ }^{22}$

Table 1 displays the risk-free rate for various parameters of loss aversion and for the standard recursive utility model with loss aversion $\gamma$ and $\bar{\gamma}$ (calculated for $\alpha=0.55$ ).

The model with loss aversion improves on the calibration of the risk-free rate even when compared to the standard recursive utility model with high risk aversion $\bar{\gamma}$. The relative impact of loss aversion is all the more salient if the coefficient of risk aversion remains reasonably low. Risk aversion must be pushed all the way up to $\gamma=25$ for the model with loss aversion $\alpha=0.55$ to yield a risk-free rate that is no longer lower than in the standard model with high risk aversion $\bar{\gamma}$ (but still improves on the standard model with risk aversion $\gamma$ ).

To match the historical level on the risk-free rate, the model with loss aversion still requires a low rate of time discount ( $\beta$ close to one). In the rest of the calibrations, I use $\beta=(0.999)^{\frac{1}{4}}$, which generates reasonable levels for the risk-free rate.

Let us now turn to the implication of the model with loss aversion for the value premium. As documented in Bansal, Dittmar, and Lundblad (2005) as well as in Hansen, Heaton, and Li (2008), the long-run risk models successfully explain the value premium on the long-term returns. Indeed, empirical research has shown value stocks have a higher covariance with long-run consumption than growth stocks, thus justifying the higher returns they yield. In Table 2, I display the value

\footnotetext{
${ }^{22}$ In contrast, in Bansal and Yaron (2004) and Bansal, Kiku, and Yaron $(2007,2009)$, the state variable $\left\{X_{t}\right\}$ is a hidden variable and its evolution, as well as the loadings of the asset returns on the shocks, are chosen to match moments on both consumption and asset returns. The calibration is thus partly tailored to fit the standard recursive utility model.
} 


\begin{tabular}{|c|c|c|c|c|c|}
\hline & \multicolumn{3}{|c|}{ model with loss aversion } & \multicolumn{2}{|c|}{ standard model } \\
\hline & $\alpha=0.10$ & $\alpha=0.25$ & $\alpha=0.55$ & risk aversion $\gamma$ & risk aversion $\bar{\gamma}$ \\
\hline \multicolumn{6}{|c|}{$\gamma=5$} \\
\hline$\beta=(0.99)^{\frac{1}{4}}$ & $3.02 \%$ & $2.91 \%$ & $2.67 \%$ & $3.10 \%$ & $2.97 \%$ \\
\hline$\beta=(0.999)^{\frac{1}{4}}$ & $2.12 \%$ & $2.01 \%$ & $1.77 \%$ & $2.19 \%$ & $2.07 \%$ \\
\hline \multicolumn{6}{|c|}{$\gamma=10$} \\
\hline$\beta=(0.99)^{\frac{1}{4}}$ & $2.89 \%$ & $2.77 \%$ & $2.49 \%$ & $2.97 \%$ & $2.68 \%$ \\
\hline$\beta=(0.999)^{\frac{1}{4}}$ & $1.98 \%$ & $1.87 \%$ & $1.58 \%$ & $2.06 \%$ & $1.78 \%$ \\
\hline \multicolumn{6}{|c|}{$\gamma=15$} \\
\hline$\beta=(0.99)^{\frac{1}{4}}$ & $2.76 \%$ & $2.63 \%$ & $2.29 \%$ & $2.84 \%$ & $2.39 \%$ \\
\hline$\beta=(0.999)^{\frac{1}{4}}$ & $1.85 \%$ & $1.72 \%$ & $1.38 \%$ & $1.93 \%$ & $1.49 \%$ \\
\hline \multicolumn{6}{|c|}{ "Risk free rate from CRSP $(1947-2010)=1.14 \%$} \\
\hline
\end{tabular}

Table 1: Risk-Free Rate

In the last two columns, the risk-free rate is derived using the standard recursive utility model with risk aversion $\gamma$ and $\bar{\gamma}=\gamma+\frac{\alpha}{1-\alpha}(\gamma-1)$ with $\alpha=0.55$.

The nominal risk-free rate is derived from CRSP 30-day-Treasury-bill returns. I correct for inflation using NIPA price indices for non-durables and services.

I use the quarterly parameters from Hansen, Heaton, and Li (2008) for the consumption process, and $\rho=1$. 


\begin{tabular}{cccccc}
\hline \hline & \multicolumn{3}{c}{ model with loss aversion } & \multicolumn{2}{c}{ standard model } \\
& $\alpha=0.10$ & $\alpha=0.25$ & $\alpha=0.55$ & risk aversion $\gamma$ & risk aversion $\bar{\gamma}$ \\
\hline \hline$\gamma=3$ & $1.45 \%$ & $2.68 \%$ & $5.20 \%$ & $0.65 \%$ & $1.37 \%$ \\
$\gamma=5$ & $2.04 \%$ & $3.29 \%$ & $5.98 \%$ & $1.23 \%$ & $2.66 \%$ \\
$\gamma=10$ & $3.53 \%$ & $4.85 \%$ & $8.05 \%$ & $2.70 \%$ & $5.92 \%$ \\
\hline \multicolumn{4}{c}{ Value Premium from Fama-French $(1947-2010)=4.22 \%$} \\
\hline \hline
\end{tabular}

Table 2: Value Premium

Annualized value premia for various values of loss aversion $\alpha$ and risk aversion $\gamma$. In the last columns, the value premium is derived using the standard recursive utility model with risk aversion $\gamma$ and $\bar{\gamma}=$ $\gamma+\frac{\alpha}{1-\alpha}(\gamma-1)$ with $\alpha=0.55$.

The historical value premium is calculated from the five portfolios sorted on book-to-market in Kenneth French's website (1926-2011).

I use the quarterly parameters from Hansen, Heaton, and $\operatorname{Li}(2008)$ and $\beta=(0.999)^{\frac{1}{4}}, \rho=1$.

premium for the standard recursive utility model with risk aversion $\gamma$ and $\bar{\gamma}$ (calculated for a loss aversion coefficient $\alpha=0.55$ ), and for the model with loss aversion. The value premium is calculated as the difference in long-run returns between the portfolio with the highest bookto-market ratio (value portfolio) and the portfolio with the lowest book-to-market ratio (growth portfolio) using five portfolios sorted on book-to-market ratios as in Fama and French (1992).

The model with loss aversion $\alpha=0.55$ can explain the value premium for a risk aversion coefficient of $\gamma=3$ (and $\bar{\gamma}=5.5$ ). Even with loss aversion $\alpha=0.25$, the model explains most of the value premium for $\gamma=5$ (and $\bar{\gamma}=6.3$ ). In contrast, the standard recursive utility model requires $\gamma=15$ to explain the value premium.

Finally, let us turn to the equity premium. Table 3 displays the long-run equity premium for various parameters of loss aversion and for the standard recursive utility model with loss aversion $\gamma$ and $\bar{\gamma}$ (calculated for $\alpha=0.55)$. I find the covariation between the market returns and the shocks to aggregate consumption, both immediate and long-term, is too low in the data to generate the equity premium at reasonable levels of risk aversion. However, as discussed in section 2.2, the model with loss aversion improves on the calibration of the equity premium even when compared to the standard recursive utility model with high risk aversion $\bar{\gamma} \cdot{ }^{23}$ The model with loss aversion $\alpha=0.55$ explains $35 \%$ of the historical equity premium when $\gamma=10$. For this level of risk aversion, the standard recursive utility model explains only $10 \%$ of the equity premium, and the

\footnotetext{
${ }^{23}$ The relative impact of loss aversion is all the more salient if the coefficient of risk aversion remains reasonably low $(\gamma \leq 20)$. For $\gamma \geq 25$, the model with loss aversion $\alpha=0.55$ no longer improves on the standard model with high risk aversion $\bar{\gamma}$ (but still improves on the standard model with risk aversion $\gamma$ ).
} 


\begin{tabular}{cccccc}
\hline \hline & \multicolumn{3}{c}{ model with loss aversion } & \multicolumn{2}{c}{ standard model } \\
& $\alpha=0.10$ & $\alpha=0.25$ & $\alpha=0.55$ & risk aversion $\gamma$ & risk aversion $\bar{\gamma}$ \\
\hline \hline$\gamma=10$ & $0.94 \%$ & $1.29 \%$ & $2.14 \%$ & $0.72 \%$ & $1.57 \%$ \\
$\gamma=15$ & $1.34 \%$ & $1.72 \%$ & $2.74 \%$ & $1.11 \%$ & $2.44 \%$ \\
$\gamma=20$ & $1.74 \%$ & $2.16 \%$ & $3.39 \%$ & $1.50 \%$ & $3.31 \%$ \\
\hline \multicolumn{6}{c}{ Equity Premium from CRSP $(1947-2010)=6.09 \%$} \\
\hline \hline
\end{tabular}

Table 3: Equity Premium

Annualized equity premia for various values of loss aversion $\alpha$ and risk aversion $\gamma$. In the last columns, the equity premium is derived using the standard recursive utility model with risk aversion $\gamma$ and $\bar{\gamma}=$ $\gamma+\frac{\alpha}{1-\alpha}(\gamma-1)$ with $\alpha=0.55$.

The historical equity premium is calculated from CRSP value-weighted portfolio returns minus CRSP 30-day-Treasury-bill returns.

I use the quarterly parameters from Hansen, Heaton, and $\operatorname{Li}(2008)$ and $\beta=(0.999)^{\frac{1}{4}}, \rho=1$.

standard model with high risk aversion $\bar{\gamma}$ explains $25 \%$ of the equity premium.

Increasing the frequency of the consumption process would increase the implied equity premium values, both through the loss aversion specification, as noted in Benartzi and Thaler (1995), and through the persistence of the consumption drift, as in Bansal, Kiku, and Yaron (2009). Because the relevant macro-data is available for quarterly frequency, I limit the analysis to the empirical set up of Hansen, Heaton, and Li (2008), while keeping in mind that a monthly frequency would improve the empirical fit of my model.

Malloy et al. (2009) adapt the empirical set-up of Hansen, Heaton, and Li (2008) to stockholders' consumption (in contrast to the aggregate consumption). The authors argue the relevant Euler Equation for equity is the one resulting from the optimization problem of the stock market's participants. Using stockholders' consumption would also improve on the calibration of the equity premium.

As I have shown in tables 1, 2, and 3, the model with loss aversion improves the calibration of the risk-free rate, the value premium and the equity premium, even when compared to the standard recursive utility model with high risk aversion $\bar{\gamma}$. Keep in mind, however, that these results could always be matched using the standard recursive utility model. Indeed, this calibration exercise does not allow one to choose between a model with loss aversion $\alpha$ and risk aversion $\gamma$ and a model with standard recursive utility and risk aversion $\widetilde{\gamma}>\bar{\gamma}=\gamma+\frac{\alpha}{1-\alpha}(\gamma-1)$. In the next sections, I turn to the truly differentiating feature of my model, the cross-sectional effect of loss aversion. 


\subsection{Negative Premium for Skewness}

In Harvey and Siddique (2000), the authors analyze the empirical price impact of skewness. They find that, for a given returns volatility, assets with lower skewness in the returns distribution yield higher expected returns than assets with higher skewness in the returns distribution: a negative premium for skewness obtains. In this section, I analyze the predictions of my model regarding the impact of skewness. I show that loss aversion offers a novel theoretic justification for the negative premium for skewness.

Consider a cross-section of assets with log-normal returns $\left\{R_{i, t+1}\right\}$ as in Eq. (12). I suppose $\left\{\Sigma_{R, i}\right\}$, the log-returns loadings on the log-consumption shocks (which I refer to as the aggregate shocks), are positive, and I order them such that $\left|\Sigma_{R, 1}\right| \leq\left|\Sigma_{R, 2}\right| \leq \ldots \leq\left|\Sigma_{R, N}\right|$. The same ordering applies for the aggregate volatilities, $\sigma_{1} \leq \sigma_{2} \leq \ldots \leq \sigma_{N}$, and aggregate skewnesses, $s_{1} \leq s_{2} \leq \ldots \leq s_{N}$.

To isolate the impact of skewness on the expected returns, I wish to compare assets with same aggregate volatility. Choose a reference asset $i_{0} \cdot{ }^{24}$ Its loading on the consumption shocks, $\left|\Sigma_{R, i_{0}}\right|$, determines its aggregate volatility $\sigma_{i_{0}}$ and skewness $s_{i_{0}}$. In the cross-section of assets I consider, all assets $\left\{i \leq i_{0}\right\}$ have lower aggregate volatilities and skewnesses than the reference asset, and all assets $\left\{i \geq i_{0}\right\}$ have higher aggregate volatilities $\left\{\sigma_{i}\right\}$ and skewnesses $\left\{s_{i}\right\}$ than the reference asset.

To equalize the aggregate volatilites of all assets in the cross-section, I lever-up assets $\left\{i \leq i_{0}\right\}$, and lever-down assets $\left\{i \geq i_{0}\right\}$. By leveraging asset $i$ by a factor $k_{i}$, I modify its aggregate volatility and expected excess returns linearly to $k_{i} \sigma_{i}$ and $k_{i}\left(R_{i}-R_{f}\right)$, while keeping its aggregate skewness $s_{i}$ unchanged. I thus obtain a cross-section of assets with the same aggregate volatility $\sigma_{i_{0}}$, but expected excess returns $\left\{k_{i}\left(R_{i}-R_{f}\right)\right\}$ and aggregate skewnesses $\left\{s_{i}\right\}$ that vary in the crosssection.

In Figure 10, I display the expected excess returns $\left\{R_{i}-R_{f}\right\}$ as they vary with the aggregate volatilities $\left\{\sigma_{i}\right\}$, in the loss aversion model with $\alpha=0.55$. For illustrative purposes, I consider a cross-section of assets with positive loadings on the immediate consumption shocks only. For the assets I consider, as the aggregate volatility increases, so does the aggregate skewness in the returns distribution. I find that, in line with the results of section 2.2, this cross-section of expected excess returns increases non-linearly with the aggregate volatilities. Because the law of one price

\footnotetext{
${ }^{24}$ Harvey and Siddique (2010) choose the market portfolio as the reference asset.
} 


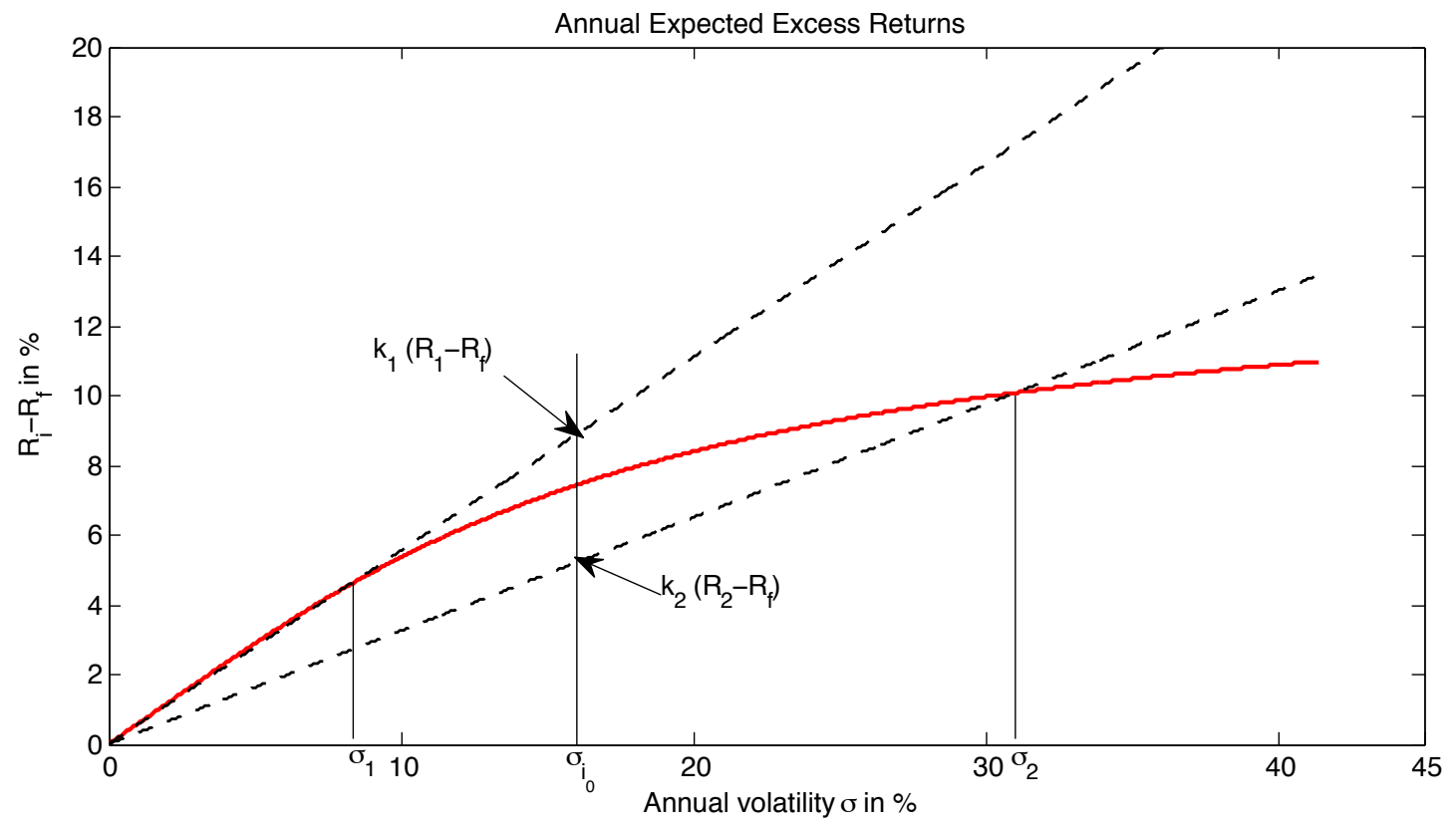

Figure 10: Leveraging on the Cross-Section of Assets

The graph displays the annualized expected excess returns in the loss aversion model, with $\alpha=0.55$, as they vary with the annual aggregate volatilities $\left\{\sigma_{i}\right\}$ implied by loadings $\left[\begin{array}{cc}\Sigma_{i} & 0\end{array}\right]$, with $\Sigma_{i}$ positive and increasing in $i$.

I use the quarterly parameters from Hansen, Heaton, and Li (2008) with $\gamma=5, \beta=(0.999)^{\frac{1}{4}}$.

applies, this implies that higher moments must be priced by the loss aversion model.

In Figure 10, I also illustrate the leverage methodology described above. I lever-up asset 1 with $\left(\sigma_{1}=8 \%\right)<\left(\sigma_{i_{0}}=16 \%\right)\left(\right.$ and $\left.k_{1}=2\right)$, and lever-down asset 2 with $\left(\sigma_{2}=32 \%\right)>\left(\sigma_{i_{0}}=16 \%\right)$ (and $\left.k_{2}=0.5\right)$. The returns $k_{1}\left(R_{1, t+1}-R_{f, t}\right), k_{2}\left(R_{2, t+1}-R_{f, t}\right)$, and $R_{i_{0}, t+1}-R_{f, t}$ have same aggregate volatility but different skewnesses $s_{1}<s_{i_{0}}<s_{2}$. Observe that the loss aversion model generates $k_{1}\left(R_{1}-R_{f}\right)>R_{i_{0}}-R_{f}>k_{2}\left(R_{2}-R_{f}\right)$, and thus a negative premium for skewness.

In Table 4, I provide quantitative measures for the negative premium for skewness in the model with loss aversion $\alpha=0.55$. Using quarterly returns from CRSP (1926-2010), I find a returns skewness of 1.8 for the market portfolio. With a reference asset similar to the market portfolio (same volatility and skewness), the loss aversion model results in a negative premium for skewness equal to $17 \%$ of the equity premium, about a third of $57 \%$, the historical negative premium for skewness from Harvey and Siddique (2000).

In Harvey and Siddique (2000), the negative premium for skewness obtains from directly modifying the stochastic discount factor (so it is linear in both the market returns and the square of the 


\begin{tabular}{cccc}
\hline & & & \\
& $k_{1}\left(R_{1}-R_{f}\right)-k_{2}\left(R_{2}-R_{f}\right)$ & $R_{i_{0}}-R_{f}$ & $\frac{k_{1}\left(R_{1}-R_{f}\right)-k_{2}\left(R_{2}-R_{f}\right)}{R_{i_{0}}-R_{f}}$ \\
\hline$s_{i_{0}}=1$ & $0.61 \%$ & $9.24 \%$ & $7 \%$ \\
$s_{i_{0}}=1.8$ & $1.53 \%$ & $9.05 \%$ & $17 \%$ \\
$s_{i_{0}}=4$ & $2.64 \%$ & $8.18 \%$ & $32 \%$ \\
\hline \hline & Harvey and Siddique $(2000)=3.5 \%(=57 \%$ of Equity premium $)$ \\
\hline \hline
\end{tabular}

Table 4: Negative Skewness Premium

The reference asset $i_{0}$ has annual volatility $\sigma_{i_{0}}=16 \%$ and quarterly skewness $s_{i_{0}}$. This table displays the annual excess returns of asset $i=1$ with skewness $s_{1}=\frac{s_{i_{0}}}{2}$ versus asset $i=2$ with skewness $s_{2}=3 s_{i_{0}}$.

I use the quarterly parameters from Hansen, Heaton, and $\operatorname{Li}(2008)$ with $\gamma=5, \beta=(0.999)^{\frac{1}{4}}$, and the model with loss aversion $\alpha=0.55$.

market returns). In contrast, my consumption-based asset pricing model with loss aversion is not tailored to address the skewness premium. Barberis and Huang (2008) also point out a relation between loss aversion and the pricing of skewness in asset returns. Their model, however, requires to incorporate the modified probability weightings of Tversky-Kahneman (1992) cumulative prospect theory in order to generate this result, in contrast to my model of loss aversion.

\subsection{Prediction for CAPM Alphas}

In this section, I analyze the predictions of my model for the fit of the CAPM. Black, Jensen, and Scholes (1972) point out that the security market line (the excess returns as a function of beta, the exposure to market risk) for U.S. stocks is too flat relative to the CAPM model. They find the intercept of the security market line is not zero (as predicted by the CAPM) but a positive return, of about 1.5\% annually. Frazzini and Pedersen (2010) show that this empirical result is valid for a wider class of assets (U.S. equities, 20 global equity markets, Treasury bonds, corporate bonds, and futures) and has been persistent over time. They also find a high intercept for the security market line of U.S. stocks, in a five-factor model that accounts for market, value, size, momentum, and liquidity risk. My model with loss aversion offers a novel theoretical justification for this central empirical result.

Because of the poor correlation between the market returns and the consumption shocks in the data, consumption-CAPM regressions are typically poor at fitting asset returns. To conduct a meaningful analysis of my consumption-based asset pricing model, I assume that the shocks to the 


\begin{tabular}{cccc}
\hline \hline & & & \\
& Small $\beta$ Portfolio & Market Portfolio & High $\beta$ Portfolio \\
\hline Expected Excess Returns & $7.50 \%$ & $9.05 \%$ & $15.34 \%$ \\
CAPM $\beta$ & 0.8 & 1 & 2 \\
CAPM $\alpha$ & $0.32 \%$ & 0 & $-2.77 \%$ \\
Skewness & 1.4 & 1.8 & 4.2 \\
\hline \hline CAPM Intercept $=2.3 \%(=25 \%$ of Equity premium $)$ \\
\hline CAPM Intercept in Frazzini and Pedersen $(2010)=2.7 \%(=45 \%$ of Equity premium $)$ \\
\hline \hline
\end{tabular}

Table 5: CAPM intercept

The reference asset (market portfolio) has CAPM beta of one, annual volatility $\sigma_{i_{0}}=16 \%$, and quarterly skewness 1.8. I fit a line between the asset with $\beta=0.8$ and the asset with $\beta=2$, and display its intercept. I use the quarterly parameters from Hansen, Heaton, and $\operatorname{Li}(2008)$ with $\gamma=5, \beta=(0.999)^{\frac{1}{4}}$, and the model with loss aversion $\alpha=0.55$.

market returns are perfectly correlated with the immediate consumption shocks. ${ }^{25}$ As in section 3.2 , let's consider a cross-section of assets with log-normal returns $\left\{R_{i, t+1}\right\}$ as in Eq. (12). I order $\left\{\Sigma_{R, i}\right\}$, the log-returns loadings on the immediate log-consumption shock (and thus on the shock to the market returns), such that $0 \leq \Sigma_{R, 1} \leq \Sigma_{R, 2} \leq \ldots \leq \Sigma_{R, N}$. The same ordering applies for the aggregate volatilities, $\sigma_{1} \leq \sigma_{2} \leq \ldots \leq \sigma_{N}$, and CAPM betas, $\beta_{1} \leq \beta_{2} \leq \ldots \leq \beta_{N}$.

In Figure 11, I display the expected excess returns $\left\{R_{i}-R_{f}\right\}$ as they vary with the CAPM betas $\left\{\beta_{i}\right\}$, in the loss aversion model with $\alpha=0.55$. For this cross-section of assets, the expected excess returns increase with the CAPM betas in a non-linear way. I find a strictly positive intercept when fitting a line between the returns of $\beta_{i}=0.8$ and the returns of $\beta_{i}=2 .{ }^{26}$

The results of Figure 11 do not violate the law of one price. Indeed, remember from section 3.2 that, for this cross-section of assets, the skewness in the returns distribution strictly increases with the CAPM beta. As I have shown above, higher moments in the returns distribution are priced by the loss aversion model.

In Table 5, I provide quantitative measures for the fit of the CAPM in the model with loss aversion $\alpha=0.55$. With a reference asset similar to the market portfolio (same volatility and skewness), the loss aversion model can explain more than half of the positive intercept found in Frazzini and Pedersen (2010).

\footnotetext{
${ }^{25}$ The model with $\rho=1$ yields constant wealth-to-consumption ratios. This is therefore equivalent to supposing the returns on wealth are perfectly correlated with the returns of the market portfolio.

${ }^{26}$ Using quarterly returns on all U.S. equities in CRSP (1926-2009), 10 value-weighted portfolios sorted on their CAPM betas have CAPM betas between 0.75 and 1.8.
} 


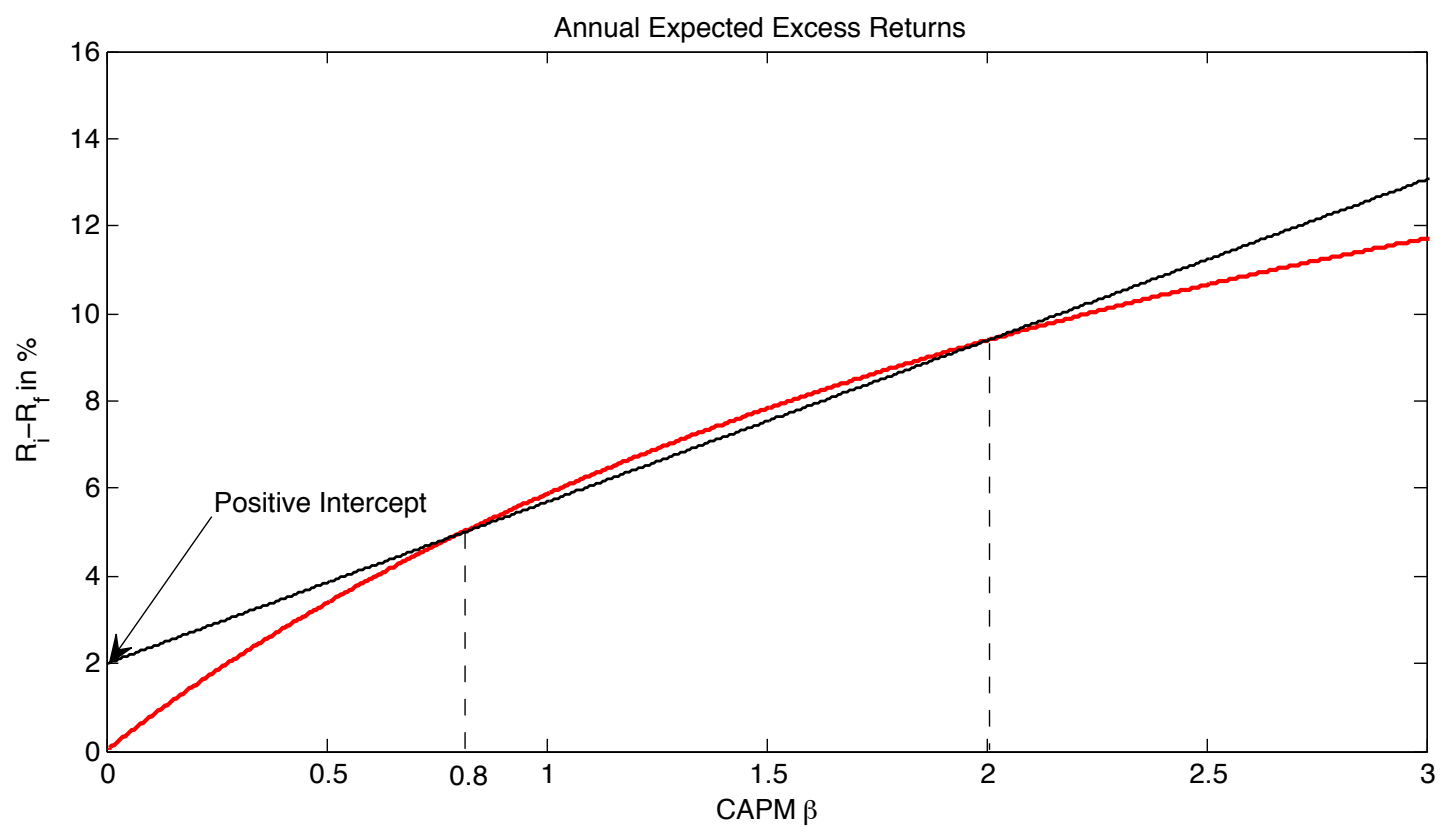

Figure 11: Prediction for the fit of the CAPM

The graph displays the annualized expected excess returns in the loss aversion model, with $\alpha=0.55$, as they vary with the CAPM betas $\left\{\beta_{i}\right\}$ implied by loadings $\left[\begin{array}{cc}\Sigma_{i} & 0\end{array}\right]$, with $\Sigma_{i}$ positive and increasing in $i$. I use the quarterly parameters from Hansen, Heaton, and Li (2008) with $\gamma=5, \beta=(0.999)^{\frac{1}{4}}$.

In the cross-section of assets I consider, the CAPM betas and the aggregate skewnesses of the returns distributions increase simultaneously, when the loadings on the aggregate shock increase. Therefore, the results of Table 5 crucially depend on a positive relation between CAPM betas and aggregate skewnesses of returns. As displayed in Table (6), using quarterly returns on all U.S. equities in CRSP (1926-2009), the 10 value-weighted portfolios sorted on CAPM betas yield a correlation between CAPM beta and skewness of $82 \% .{ }^{27}$ These empirical results validate the choice of the log-normal model of returns of Eq. (12) for the cross-sectional analysis of expected excess returns.

For a cross-section of assets with log-normal returns, the model with loss aversion justifies, qualitatively and quantitatively, a security market line flatter than the CAPM. Other models in the literature rely on borrowing constraints and heterogeneous agents to obtain the desired results on the security market line (e.g., Black (1972, 1992); Brennan (1971); Frazzini-Pedersen (2010)). My model offers a novel justification for this central issue in financial economics.

\footnotetext{
${ }^{27}$ The are measures of skewness and not aggregate skewness however.
} 


\begin{tabular}{ccccccccccc}
\hline \hline \multicolumn{10}{c}{ Value-Weighted Portfolios Sorted on CAPM $\beta$} \\
\hline & Low $\beta$ & 2 & 3 & 4 & 5 & 6 & 7 & 8 & 9 & High $\beta$ \\
\hline$\beta$ & 0.75 & 0.86 & 0.97 & 1.1 & 1.2 & 1.3 & 1.4 & 1.5 & 1.6 & 1.8 \\
Skewness & 3.7 & 2.5 & 3.2 & 4.2 & 4.5 & 5.4 & 4.7 & 4.9 & 4.8 & 5.6 \\
\hline \hline
\end{tabular}

Table 6: Quarterly Skewness Results

\section{Conclusion}

In this paper, I incorporate loss aversion features in a recursive model of preferences and find tractable solutions to the consumption-based asset pricing model with homogeneous agents. The model with loss aversion generates risk-price elasticities that vary with the exposure to the consumption shocks (cross-sectional effect) and that are generally higher than in the standard recursive utility model (level effect). The level effect my model with loss aversion generates allows me to match or improve on calibration exercises that use asset returns moments. More striking, I find the empirical evidence regarding the security market line relative to the CAPM and regarding the negative premium for skewness provide strong support for my model with loss aversion. 


\section{References}

Akerlof, G., Dickens, W. (1982). "The Economic Consequences of Cognitive Dissonance," American Economic Review, 72, 307-19.

Attanasio, O., Vissing-Jorgensen, A. (2003), "Stock-Market Participation, Intertemporal

Substitution, and Risk-Aversion," American Economic Review, Papers and Proceedings, 383-391.

Attanasio, O., Weber, G. (1989), "Intertemporal Substitution, Risk Aversion and the Euler Equation for Consumption," Economic Journal 99, 59-73.

Bansal, R., Dittmar, R., Lundblad, C. (2005), "Consumption, dividends, and the cross-section of equity returns," Journal of Finance 60, 1639-1672.

Bansal, R., Kiku, D., Yaron, A. (2007), "Risks for the Long Run: Estimation and Inference," Working paper.

Bansal, R., Kiku, D., Yaron, A. (2009), "An Empirical Evaluation of the Long-Run Risks Model for Asset Prices," NBER Working Papers 15504

Bansal, R., Yaron, A. (2004), "Risks for the Long Run: A Potential Resolution of Asset Pricing Puzzles," Journal of Finance 59, 1481-1509.

Barberis, N., Huang, M. (2008), "Stocks as Lotteries: The Implications of Probability Weighting for Security Prices." American Economic Review, 98, 2066-2100.

Barberis, N., Huang, M. (2009), "Preferences with Frames: A New Utility Specification that Allows for the Framing of Risks", Journal of Economic Dynamics and Control 33, 1555-1576.

Barberis, N., Huang, M., Santos, T. (2001), "Prospect theory and asset prices," Quarterly Journal of Economics 116, 1-53.

Barberis, N., Huang, M., Thaler, R. (2006) "Individual preferences, monetary gambles, and stock market participation: a case for narrow framing," American Economic Review 96, 1069-1090.

Barro, R., Nakamura, E., Steinsson, J., Ursúa, J. (2010), "Crises and Recoveries in an Empirical Model of Consumption Disasters," NBER Working Papers 15920. 
Beaudry, P., van Wincoop, E. (1996), "The Intertemporal Elasticity of Substitution: An Exploration Using A Panel of State Data," Economica 63, 495-512.

Beeler, J., Campbell, J. (2009), "The Long-Run Risks Model and Aggregate Asset Prices: An Empirical Assessment," NBER Working paper 14788.

Benartzi, S, Thaler, R. (1995), "Myopic Loss Aversion and the Equity Premium Puzzle," Quarterly Journal of Economics 110, 73-92.

Black, F. (1972), "Capital market equilibrium with restricted borrowing," Journal of business 45, 3, pp. 444-455.

Black, F. (1992), "Beta and Return," The Journal of Portfolio Management, 20, pp. 8-18.

Black, F., M.C. Jensen, and M. Scholes (1972), "The Capital Asset Pricing Model: Some Empirical Tests," In Michael C. Jensen (ed.), Studies in the Theory of Capital Markets, New York, pp. 79-121.

Bonomo, M., Garcia, R., Meddahi, N., Tédongap, R. (2010) "Generalized Disappointment Aversion, Long Run Volatility Risk and Asset Prices," TSE Working Papers 10-187, Toulouse School of Economics (TSE).

Brennan, M.J., (1971), "Capital market equilibrium with divergent borrowing and lending rates," Journal of Financial and Quantitative Analysis 6, 1197-1205.

Campbell, J. (1999), "Asset prices, Consumption and the Business Cycle," Handbook of Macroeconomics, Volume 1, pp. 1231-1303; John B. Taylor and Michael Woodford, editors.

Campbell, J., Cochrane, J. (1999), "By Force of Habit: A Consumption-Based Explanation of Aggregate Stock Market Behavior," Journal of Political Economy 107, 205- 255.

Chabi-Yo, F., Leisen, D., Renault, E. (2007), "Implications of Asymmetry Risk for Portfolio Analysis and Asset Pricing," working paper.

Crawford, V., Meng, J. (2008), “New York City Cabdrivers' Labor Supply Revisited:

Reference-Dependence Preferences with Rational-Expectations Targets for Hours and Income," University of California at San Diego, Economics Working Paper Series 557104, Department of Economics, UC San Diego. 
Dillenberger, D., Rozen, K. (2010), "Disappointment Cycles," PIER Working Paper Archive 10-028, Penn Institute for Economic Research, Department of Economics, University of Pennsylvania.

Duffie, D., Lyons, P. (1992), "PDE solutions of stochastic differential utility," Journal of Mathematical Economics 21 (1992) 577-606.

Eil, D., Lien, J. (2011), "Staying Ahead and Getting Even: Evidence from Decisions of Online Poker Experts", working paper

Engegelhardt, G., Kumar, A. (2008), "The Elasticity of Intertemporal Substitution: New Evidence from 401(k) Participation," Working paper 0812, Federal Reserve Bank of Dallas.

Epstein, L., Zin, S. (1989), "Substitution, risk aversion, and the temporal behavior of consumption and asset returns: a theoretical perspective," Econometrica 57, 937-969.

Fama, E., French, K. (1992), "The Cross-Section of Expected Stock Returns," Journal of Finance $59,427-465$.

Frazzini, A., Pedersen, L. (2010), "Betting Against Beta," NBER Working Papers 16601.

Frederick, S., Loewenstein, G. (1999), "Hedonic Adaptation," in "Well being: The foundations of hedonic psychology", pp. 302-329; Diener, E., Kahneman, D., Schwarz, N., editors.

Gneezy, U., List, J., Wu, G. (2006) "The Uncertainty Effect: When a Risky Prospect Is Valued Less Than Its Worst Possible Outcome," The Quarterly Journal of Economics, 121, 1283-1309.

Gruber, J. (2006), "A Tax-Based Estimate of the Elasticity of Intertemporal Substitution," NBER Working paper 11945.

Gul, F. (1991), "A Theory of Disappointment Aversion," Econometrica, 59, 667-86.

Guvenen, F. (2006), "Reconciling Conflicting Evidence on the Elasticity of Intertemporal Substitution: A Macroeconomic Perspective," Journal of Monetary Economics 53, 1451-1472.

Hall, R. (1988), "Intertemporal Substitution in Consumption," Journal of Political Economy 96, 339-357. 
Hansen, L., Lee, J., Polson, N., Yae, S. (2011), "Assessing the Recursive Utility Model," working paper.

Hansen, L., Heaton, J., Li, N. (2008), "Consumption strikes back?," Journal of Political Economy, 116, 260-302.

Hansen, L., Heaton, J., Lee, J., Roussanov, N. (2007), "Intertemporal Substitution and Risk Aversion," Handbook of Econometrics 6.

Hansen, L., Singleton, K. (1982), "Generalized Instrumental Variables Estimation of Nonlinear Rational Expectations Models," Econometrica 63, 767-804.

Harvey, C., Siddique, A. (2000), "Conditional skewness in asset pricing tests," Journal of Finance $55,1263-1295$.

Kahneman, D., Tversky, A. (1979), "Prospect theory: an analysis of decision under risk," Econometrica 47, 263-291.

Koszegi, B., Rabin, M. (2006), "A Model of Reference-Dependent Preferences," Quarterly Journal of Economics, 121, 1133-65.

Koszegi, B., Rabin, M. (2007), "Reference-dependent risk attitudes," American Economic Review 97, 1047-1073.

Koszegi, B., Rabin, M. (2009), "Reference-Dependent Consumption Plans," American Economic Review, 99, 909-936.

Malloy, C., Moskowitz, T., Vissing-Jorgensen, A. (2009), "Long-Run Stockholder Consumption Risk and Asset Returns," Journal of Finance, 64, 2427-2479.

Matthey, A. (2010), "The Influence of Priming on Reference States," Games, MDPI, Open Access Journal, 1, 34-52.

Melino, A., Yang, A. (2003), "State dependent preferences can explain the equity premium puzzle," Review of Economic Dynamics 6, 806-830.

Mulligan, C. (2004), "What do Aggregate Consumption Euler Equations Say about the Capital Income Tax Burden?," NBER Working Papers 10262. 
Pastor, L, Stambaugh, R. (2003), "Liquidity risk and expected stock returns," Journal of Political Economy 111, 642-685.

Post, T., van den Assem, M., Baltussen, G., Thaler, R. (2008), "Deal or No Deal? Decision Making under Risk in a Large-Payoff Game Show," American Economic Review, 98, 38-71.

Rabin (2000), "Risk Aversion and Expected-Utility Theory: A Calibration Theorem,"

Econometrica, 68, 1281-1292.

Routledge, B., Zin, S. (2010), "Generalized Disappointment Aversion and Asset Prices," Journal of Finance, 65, 1303-1332.

Schroder, M., Skiadas, C. (1999), "Optimal Consumption and Portfolio Selection with Stochastic Differential Utility," Journal of Economic Theory 89, 68-126.

Sprenger, C. (2010), “An Endowment Effect for Risk: Experimental Tests of Stochastic Reference Points," working paper.

Vissing-Jorgensen, A. (2002), "Limited Asset Market Participation and the Elasticity of Intertemporal Substitution," Journal of Political Economy 110, 825-853.

Tversky, A., Kahneman, D. (1992), "Advances in Prospect Theory: Cumulative Representation of Uncertainty." Journal of Risk and uncertainty, 5, 297-323.

Yogo, M. (2008), "Asset Prices Under Habit Formation and Reference-Dependent Preferences," Journal of Business \& Economic Statistics, American Statistical Association, 26, 131-143. 